\title{
LOS PODERES NORMATIVOS DE LA GENERALITAT DE CATALUNYA
}

\author{
353.072.1 (Cataluña)
}

por

\section{Javier Salas}

Profesor Agregado de Derecho Administrativo en la Universidad de Barcelona

SUMARIO: I. INTRODUCCION.-II. LA POTESTAD LEGISLATIVA: 1. Titularidad y eJERCicio. 2. Ambito material: A) Materias de competencia propia o estatutaria: a) En torno al concepto de competencia exclusiva y sus consecuencias. b) Algunas precisiones en relación con determinadas materias: a') Seguridad Social y televisión. b') Materias incluidas en el articulo 12 del Estatuto. c') Breves conclusiones. c) Supuestos de no coincidencia entre exclusividad de la competencia y potestad legislativa. d) Enseñanza, policia y administración de justicia. B) Materias de atribución extraestatutaria. 3. LímITES: A) Generales: a) Ratione materiae. b) Katione territorii. c) Ratione temporis. d) Otros límites derivados de determinados preceptos constitucionales. B) Específicos.-III. LA POTESTAD REGLAMENTARIA: 1. SU PLANTEAMIENTO A NIVEL CONSTITUCIONAL Y ESTAtutario. 2. Titularidad. 3. Ambito. 4. Límites. 5. Relaciones ENTRE LEY Y REgLAMENTO--IV. EL CONTROL DE LAS POTESTADES NORMATIVAS: 1. PlanTEAMIENTO GENERAL Y CONtroles extrajudiciales. 2. Control por el Tribunal Consti. tucional. 3. Control por los Tribunales CONTENCiOsos. 


\section{INTRODUCCION}

Aunque pueda parecer otra cosa a primera vista, tras una lectura poco reflexiva del título del presente trabajo, el alcance de éste no queda reducido, ni mucho menos, al de índole técnico-jurídica, sino que va más allá, concretamente, al núcleo mismo de los conceptos de autonomía y de autogobierno y, en consecuencia, a sus implicaciones en el plano político.

En efecto, si tales conceptos han de tener algún sentido, referidos como están, de acuerdo con los principios contenidos en nuestra Constitución (arts. 2 y 143, 1), a las Comunidades Autónomas, no pueden dejar de remitir, por un lado, a la potestad normativa-genéricamente entendida-de aquéllas y, por otra, a la concreta potestad legislativa-en sú acepción más estricta-, que, nótese bien, es la que vendría, en definitiva, a configurar a tales entidades como sujetos que gozan de un verdadero poder y de una genuina dirección política en el ámbito de determinadas materias enunciadas en la Carta fundamental y concretadas en el correspondiente Estatuto de Autonomía. En otro caso y, en especial, faltando la potestad legislativa, estaríamos ante el supuesto de una mera descentralización administrativa.

Dando por descontado que la Constitución habilita para asumir tal poder por parte de las Comunidades Autónomas y que el Estatuto de Catalunya lo ha consagrado en relación con determinadas materias, debe abordarse la cuestión relativa tanto a los términos en que ello se ha producido como al alcance de los demás poderes normativos de la Generalitat distintos del estrictamente legislativo.

El tema no está, desde luego, nada claro en algunos aspectos -esenciales, por otra parte-en el Estatuto. De ahí la oportunidad e incluso la necesidad de realizar a tal propósito una serie de reflexiones, sin duda provisionales y a reserva de ulteriores juicios, tanto propios como ajenos, sobre tan relevante problemática. Una problemática, por lo demás, estrechamente ligada a la cuestión de las competencias atribuidas a la Generalitat, sobre la que aquí no haremos más que las referencias imprescindibles, habida cuenta del estudio que a aquélla dedica en estas mismas páginas JOAQUín TORNOS, al que nos remitimos por completo.

Antes de entrar, sin embargo, en la consideración específica de las potestades propiamente normativas-legislativa y reglamentariade la Generalitat, conviene aludir, siquiera sea de modo sucinto, a otra potestad-compartida con el Estado-cual es la potestad estatutaria. Una potestad, nótese bien, de orden no exclusivamente norma- 
tivo, sino a la vez y fundamentalmente de carácter organizativo (vid. el art. 147, 2, de la Constitución). Una potestad, además, cuyo ejercicio no queda en manos solamente de la Asamblea de Parlamentarios elegidos en el territorio de lo que aspira a ser la Comunidad Autónoma o del Parlamento de ésta, una vez constituida, sino que una y otro, según el momento de referencia, comparten con las Cortes Generales-e incluso con el propio pueblo que está a la base de dicha Comunidad in fieri o ya constituida-a través de un complejo procedimiento regulado tanto en la Constitución (art. 151 y Disposición transitoria segunda) como en el mismo Estatuto (arts. 56 y 57, con apoyo en el art. 147, 2, de aquella Ley fundamental), en este caso, naturalmente, por lo que respecta a la reforma o modificación del propio texto estatutario. De la rica problemática inherente a la potestad estatutaria-ejercida, como se ha dicho, por tres instancias diferentes-interesa aquí simplemente destacar lo que tiene de pacto o acuerdo en orden a la formulación de un texto-el Estatuto, originario o reformado-que ninguna de aquellas instancias-Cortes Generales, Asamblea de parlamentarios o Parlament y pueblo de Catalunya-puede imponer a las demás sin su consentimiento o, al menos, en el peor de los casos, sin su intervención. Pacto, fundamentalmente, entre el poder legislativo del Estado y los representantes parlamentarios de Catalunya en las Cortes, primero, y luego, en el propio Parlament, que hace revivir-en la actualidad con pleno sentido, tanto político como jurídico-la vieja y discutida técnica de la "Ley paccionada".

Ahora bien, dejando al margen que el Estatuto, como producto de la potestad a que acabo de referirme, constituye la fuente misma de los poderes normativos de la Generalitat, es el estudio de éstos, como poderes derivados de aquél -y, en último término, de la Constitución-el que hemos de abordar a continuación.

\section{LA POTESTAD LEGISLATIVA}

\section{Titularidad y EJERCicio}

De acuerdo con los artículos 30, 1, y 33, 1, del Estatuto de Catalunya, el Parlament tiene atribuida la potestad legislativa de la Generalitat de manera análoga a como el artículo 66, 2, de la Constitución otorga la potestad legislativa del Estado a las Cortes Generales. Existe, pues, una atribución expresa de tal potestad en 
términos tales que disipan-junto con los de otros preceptos del mismo Estatuto-cualquier duda que pudiera haber al respecto derivada de la sola lectura de la Constitución. El reconocimiento de dicha potestad me parece algo indiscutible y, en consecuencia, no vale la pena insistir utilizando otros argumentos "a mayor abundamiento" (vid. la excelente obra de MuÑo\%. MaChaDo). Con dicha afirmación no están, ni mucho menos, resueltas todas las cuestiones implicadas en la configuración y ejercicio de tal poder. Veamos seguidamente las más importantes.

En primer lugar, la de si la titularidad del Parlament admite o no en algún caso la posibilidad de ejercicio de la potestad legislativa por parte del Consell Executiu o Govern de la Generalitat. Pues bien, en este caso, la respuesta se ha quedado a medio camino de lo previsto tanto en la esfera estatal como en el Proyecto de Estatuto aprobado por la Asamblea de Parlamentarios. En efecto, de las dos técnicas posibles-legislación delegada y Decretos-Leyes-, ninguna de las cuales, por cierto, se recogía en el Estatuto de 1932, el texto definitivo del Estatuto de 1979 ha sancionado únicamente la primera en su artículo 33, l, según el cual la potestad legislativa "sólo será delegable en el Conscjo Ejecutivo o Gobicrno en términos idénticos a los que para el supuesto de delegación de las Cortes Generales al Gobierno establecen los artículos 82, 83 y 84 de la Constitución”. Preceptos que, como es sabido, establecen las materias excluidas, los requisitos o condiciones de ejercicio de la delegación y los controles sobre el producto normativo elaborado en base a ésta. La remisión en bloque a dichos preceptos constitucionales ha de entenderse, no obstante, y a pesar de la contundente expresión empleada-"en términos idénticos"-, con alguna salvedad: concretamente, la relativa a la exclusión del ámbito de la legislación delegada (estatal) de las materias regulables por Ley Orgánica (art. 82, 1). En la medida en que tales materias están reservadas a una Ley estatal (de una determinada clase: la orgánica) pingún sentido tiene su exclusión del ámbito de la legislación delegada de la Generalitat.

Por otro lado, aunque el Estatuto no se ha remitido en este punto al artículo 85 de la Constitución, no creo que haya dificultad alguna de orden constitucional o estatutario en denominar Decretos legislativos a las "disposiciones" del Govern de la Generalitat "que contengan legislación delegada" del Parlament de la misma. La procedencia subjetiva y la firma y refrendo de aquéllos permitiría fácilmente distinguirlos de los emanados por el Gobierno del Estado. $\mathrm{Al}$ margen de los demás puntos contenidos en los artículos 82 a 81 
de la Constitución, y sobre los cuales no voy a insistir aquí, me parece oportuno destacar que, de acuerdo con el artículo 33, 1, del Estatuto -que traslada al ámbito de la Generalitat lo que el primero de aquéllos prescribe en relación con la esfera estatal-, el Parlament de Catalunya sólo puede delegar su potestad legislativa al Consell Executiu o Govern y no a ningún otro órgano (por ejemplo, a un Ministro o Conseller).

Como se ha dicho, la técnica del Decreto-Ley no ha sido sancionada por el Estatuto. La previsión que en tal sentido figuraba en el Proyecto aprobado por la Asamblea de Parlamentarios (art. 32, 2) ha quedado, pues, excluida del texto definitivamente aprobado. En consecuencia, el Gobierno de la Generalitat no podrá dictar normas (o actos) con valor y fuerza de Ley como no sea en base a una delegación previa del Parlament con los requisitos antes mencionados. Por muy urgente y extraordinaria que sea la necesidad que haya de afrontarse con medidas de rango legislativo. En tal caso, y siempre que se prevea en el Reglamento del Parlament, el Gobierno catalán podrá declarar la urgencia del correspondiente Proyecto de Ley en orden a una más expeditiva tramitación del mismo.

Tal como estaba redactado el precepto mencionado en el Proyecto de Estatuto ("La Ley regulará, de conformidad con los principios contenidos en el artículo 86 de la Constitución, los términos, requisitos y efectos de la competencia del Consejo ejecutivo o Gobierno para dictar, en situaciones de grave necesidad o urgencia, disposiciones legislativas provisionales en forma de Decretos-Leyes"), me parece positiva su desaparición, ya que-como he señalado en otra ocasión-considero que habría de ser el mismo Estatuto el que fijara los elementos citados, pues de dejarse en manos de una Ley de la propia Generalitat, de valor forzosamente idéntico a los DecretosLeyes a los que intentaría regular, éstos siempre podrían excepcionar, caso por caso, sus prescripciones, lo que, lógicamente, haría perder toda virtualidad a las mismas.

Bien entendido que excluida en el Estatuto la facultad a que vengo refiriéndome, creo que sería inconstitucional-además de "antiestatutaria"- la previsión de la misma en una Ley aprobada por el Parlament. Y lo digo por la tentación en que éste puede incurrir a la vista del precedente que supuso el llamado Estatuto interior de 1933, que, sin base alguna en el Estatuto de 1932, consagró tal posibilidad (art. 56).

De la potestad legislativa de la Generalitat conviene distinguir netamente, por último, la iniciativa legislativa de la misma en 
relación con las materias atribuidas a la competencia del Estado (Cortes Generales). El reconocimiento de tal iniciativa tanto en la Constitución, con carácter general en favor de las Asambleas de las. Comunidades Autónomas (art. 87, 2), como en el Estatuto en favor del Parlament de Catalunya (art. 34, 2 y 3), no supone, sin embargo, como es obvio, compartir en tal supuesto el ejercicio de la potestad legislativa, que corresponde íntegramente a las Cortes Generales. Ni el Congreso-cuando se remita a la Mesa del mismo una proposición de Ley-ni el Gobierno-cuando se solicite la adopción de un proyecto de Ley-quedan vinculados por dicha iniciativa, que uno y otro pueden libremente no tomar en consideración o rechazar. Para la defensa de las proposiciones de Ley ante el Congreso, el Parlament de Catalunya puede delegar un máximo de tres Diputados del mismo.

\section{AMBITO MATERIAI.}

Una vez resuelta la cuestión de la titularidad y formas de ejercicio de la potestad legislativa, hay que plantear el tema relativo al ámbito material $u$ objetivo de las Leyes aprobadas por el Parlament de Catalunya (y de los Decretos legislativos que, de acuerdo con las correspondientes Leyes de bases o de autorización para refundir, emane el Consell Executiu). O dicho con otras palabras: ¿en qué materias puede la Generalitat ejercer su poder legislativo?

Antes de entrar en su determinación, conviene señalar que el conjunto de tales materias puede sistematizarse en dos grandes grupos. Uno, el de las materias que podríamos llamar de competencia propia, institucional o estatutaria, en la medida en que las mismas vienen atribuidas a la Generalitat en el Estatuto, de acuerdo con los artículos 148 y 149 de la Constitución. Otro, el de las materias de atribución extraestatutaria, en cuanto que su efectiva asunción por parte de tal Comunidad Autónoma depende de la voluntad del Estado expresada a través de una Ley aprobada por las Cortes Generales en los términos y con los efectos a que se refieren los apartados 1 y 2 del artículo 150 de la Constitución. El régimen jurídico al que el ejercicio de las potestades legislativas relativas a uno y otro grupo de materias remite es diferente, sin que, por otro lado, sea homogéneo dentro de cada uno de ellos, como vamos a ver. De ahí la conveniencia de distinguir claramente los diversos tipos de 
supuestos, comenzando por la primera de las dos categorías a que se ha hecho referencia.

\section{A) Materias de competencia propia o estatutaria}

La determinación exacta de este tipo de materias no es, desde luego, nada fácil dada la ambigüedad y falta de precisión técnicojurídica de que adolecen algunos preceptos del Estatuto, comenzando por el artículo 25, 2, del mismo.

En efecto, según dicho precepto,

"En el ejercicio de sus competencias exclusivas corresponde a la Generalidad, según proceda, la potestad legislativa, la potestad reglamentaria y la función ejecutiva, incluida la inspección. En el caso de las materias señaladas en el artículo 11 de este Estatuto, o con el mismo carácter en otros preceptos del mismo, su ejercicio deberá sujetarse a las normas reglamentarias que en desarrollo de su legislación dicte el Estado."

Es decir, que según el esquema contemplado en el artículo transcrito, tendríamos que en una serie de materias-las atribuidas a la competencia exclusiva de la Generalitat-, el ente autonómico catalán asumiría, en principio, la totalidad de las potestades normativas-luego veremos con qué límites y excepciones-y la función ejecutiva, mientras que en otras actualizaría solamente esta última, puesto que el ejercicio de sus competencias deberá en tales casos "sujetarse a las normas reglamentarias que en desarrollo de su legislación dicte el Estado”.

Ahora bien, ¿qué materias están incluidas en uno y otro apartado? La cuestión es, como bien se comprenderá, de una gran trascendencia, dada la muy diferente naturaleza de las competencias ejercitables en uno y otro supuesto. De notoria relevancia en el primero, de mucha menor importancia en el segundo, ya que autonomía y autogobierno serían los conceptos a utilizar en el primer caso para definir la situación de la Generalitat, mientras que en el segundo el procedente habría de ser el de descentralización puramente administrativa, con las correlativas consecuencias en el plano del régimen jurídico aplicable. 
a) En torno al concepto de competencia exclusiva $y$ sus consecuencias

El artículo 25, 2, párrafo primero, habla de "competencias exclusivas". ¿Serán éstas solamente las calificadas formalmente como tales en determinados preceptos del Estatuto-en concreto, en los artículos 9 y 12-o también las contenidas en otros, aunque no se califiquen así de modo expreso? A favor de la primera solución estaría el argumento deducible del número 34 del artículo 9 del Estatuto, según el cual, la Generalitat tiene competencia exclusiva, a parte de en las materias enunciadas en los números 1 a 33 del mismo precepto, en "las restantes materias que se atribuyan en el presente Estatuto expresamente como de competencia exclusiva y las que, con este carácter y mediante Ley orgánica, sean transferidas por el Estado". Es decir, excepción hecha de este último supuesto-que queda, obviamente, al margen del Estatuto-, las contenidas en el artículo 12, ya citado. De acuerdo con esta tesis, el artículo 25,2 , no habría contemplado más que dos bloques de materias a los que corresponderían otras tantas potestades de la Generalitat: Legislati$v a-c o n$ las anejas reglamentarias y ejecutiva sensu stricto-, por un lado, y puramente ejecutiva, por otro. Tales bloques de materias vendrían enumerados en los artículos 9 y 12 y 11 y similares, respectivamente, del Estatuto.

En este esquema dual, sin embargo, para nada se alude a otro bloque de materias al que se refieren determinados preceptos del Estatuto y en los que se atribuye a la Generalitat el "desarrollo legislativo y la ejecución" de las mismas (arts. 10, 16 y 17), ni al supuesto del polémico artículo 15 ("Es competencia plena de la Generalidad la regulación y administración de la enseñanza..."). ¿Qué ha de entenderse por "desarrollo legislativo"? ¿Y qué por competencia "plena"? Y sobre todo, ¿qué tipo de competencias normativas podrá ejercitar la Generalitat a propósito de las materias a que aluden tales expresiones?

Una interpretación literal del artículo 25,2 , podría conducir a considerar que al no ser tales materias de competencia formalmente exclusiva de la Generalitat, ni tampoco quedar reducidas en esos casos las funciones de ésta a simple ejecución, se estaría, en realidad, en presencia de un tertium genus no pristo en aquel precepto, en relación con el cual el ente autonómico catalán tendría atribuida, además de la función ejecutiva en sentido estricto, la potestad reglamentaria, pero no la potestad legislativa. El "desarrollo legislativo" de los artículos 10, 16 y 17 sería así, a pesar de la expresión 
literal, "desarrollo reglamentario", de la misma manera que la "regulación" a que alude el artículo 15 sería solamente regulación reglamentaria.

Dicha postura, sin embargo, no me parece en absoluto de recibo por las siguientes razones. En primer lugar, competencias exclusivas no equivalen necesariamente a competencias "separadas", es decir, competencias atribuidas a un ente en relación con toda una materia con exclusión de cualquier otro, ya sea a propósito de un sector o parcela de la misma, ya sea en una determinada fase del procedimiento simple o complejo procedimental de actualización de tales competencias (distribución horizontal o vertical, respectivamente). Es cierto que existen ejemplos de competencias "separadas" atribuidas a la Generalitat en el Estatuto respecto de materias en las que el Estado no puede desarrollar función alguna como no sea utilizando-excepción hecha, seguramente, de los tres primeros números del artículo 9 de aquél-la vía de las "Leyes de armonización" a que se refiere el artículo 150,3 , de la Constitución. Tal sería el caso de los recogidos, entre otros, en los números $1,2,3,9,12,17,18,29$ y 31 , todos ellos del referido artículo 9.

Ahora bien, no es menos cierto que, junto a materias del tipo de las que acaban de citarse, en el propio artículo 9 y en la totalidad de los supuestos enunciados en el artículo 12, existen otras en las que la Generalitat comparte con el Estado las competencias ejercitables sobre las mismas. Con lo que se pone de relieve que el concepto de competencias exclusivas no es en modo alguno incompatible con el de competencias compartidas o concurrentes-no voy a entrar aquí en la distinción de estas dos últimas, ya que no es necesario a los efectos que nos interesan ahora-y viceversa. $Y$ es que, como he puesto de manifiesto en otra ocasión, lo relevante para que una competencia pueda considerarse exclusiva no es que se proyecte sobre toda una materia-concepto éste de materia sobre el que, por otro lado, habría que ponerse de acuerdo; sobre las dificultades de su determinación me remito a un reciente trabajo de T. R. FERNAN. DEz- , sino que en la medida en que se haya atribuido a un ente estén excluidos de su titularidad los demás. Pero, bien entendido, la titularidad en cuestión puede referirse bien a una parcela o sector de la entera materia-distribución horizontal-, bien a una fase o momento de un procediniento simple o a un procedimiento específico dentro de un complejo procedimental de actualización de las potestades públicas sobre aquélla (distribución vertical o en clave procedimental). 
Que puede haber competencias exclusivas a favor de la Generalitat en relación con parcelas de materias o fases procedimentales de su regulación, a pesar de que en el Estatuto no se consideren formalmente como tales, me parece de una gran trascendencia por las siguientes razones. Primera, porque los recursos contenciosos contra los actos de la Administración de la Generalitat emanados "en las materias cuya legslación corresponda en exclusiva" a dicha Comunidad Autónoma se agotan en el Tribunal Superior de Justicia de Catalunya (art. 20, 1, c), del Estatuto). Segunda, porque el Derecho catalán es "en materia de la competencia exclusiva de la Generalidad... el aplicable en su territorio con preferencia a cualquier otro" (art. 26, 1, del Estatuto, en conexión con el art. 149, 3, de la Constitución). Competencia exclusiva que tampoco en este supuesto equivale necesariamente a competencia separada, con la importante consecuencia de que, como acertadamente ha señalado T. R. FERNANDEZ, "el principio de prevalencia del Derecho estatal no puede operar en primer resorte, porque ello equivaldría, ni más ni menos, a liquidar el concepto mismo de competencia compartida y dejar en manos del Estado exclusivamente la decisión sobre todas las materias enunciadas". "Sólo después de agotadas las posibilidades interpretativas inherentes a los criterios de articulación en cada caso establecidos por el artículo 149, l y 2, y normas concordantes, será, pues, lícito acudir como última ratio-concluye el autor citado-al principio de prevalencia que consagra el artículo 149, 3"'. Y tercera, porque para poder celebrar "convenios" con otras Comunidades Autónomas aquéllos han de tener por finalidad "la gestión y prestación de servicios propios correspondientes a materias de la exclusiva competencia" de la Generalitat, convenios que están sometidos a un régimen de intervención por las Cortes Generales menos intenso que el de los "acuerdos de cooper:! ión", que serán los procedentes en defecto de tales requisitos (ant. 27, 1 y 2 del Estatuto, en relación con el art. 142, 2, de la Constitución).

Ejemplos de distribución horizontal y vertical de competencias entre el Estado y la Generalitat los hay tanto en el artículo 9 como en el 12 del Estatuto, que-como sabemos-reputan sin rebozo como exclusivas de la Generalitat las competencias sobre las materias a las que los mismos se refieren. Competencias, eso sí, no separadas, sino compartidas de uno u otro modo con el Estado. Así, habría una distribución horizontal-por sectores o parcelas dentro de una misma materia-en los supuestos a que se refieren les números 5. 13, 14 . 15, 16, 30, 32 y 33, todos ellos del artículo 9 del Estatuto. 
Por otro lado, como ejemplos de distribución vertical de competencias exclusivas-en el sentido expuesto-entre el Estado y la Generalitat podrían citarse los contenidos en todos los supuestos del artículo 12 y, entre otros, en los números 7,8 y 10 del artículo 9 .

Pues bien, la distribución vertical de competencias, tal como está articulada en los preceptos mencionados, permite al Estado (Cortes Generales) dictar la legislación básica, marco o de principio sobre la materia de que se trate y a la Generalitat (y, en concreto, al Parlament) aprobar la legislación de desarrollo de la misma, además de ejercer en base a ésta la potestad reglamentaria y la función estrictamente ejecutiva o de actuación singularizada o gestora por parte de sus órganos de gobierno y administración.

\section{b) Algunas precisiones en relación con determinadas materias}

Puestas así las cosas, ¿qué diferencia existe entre los números 7, 8 y 10 del artículo 9 y el artículo 12 , por una parte, y los artículos 10,16 y 17 , por otro, todos ellos del Estatuto? Pues ninguna, a mi modo de ver, salvo en aquellos puntos concretos en que tanto en el artículo 12 como en los dos últimos preceptos citados se especifica el tipo de competencia de la Generalitat de tal modo que debe deducirse que ésta no goza de potestad legislativa en relación con determinadas parcelas o sectores de las materias a que se refieren. En todos los demás casos tal potestad existe, aunque deba ser actualizada-como se ha dicho-en desarrollo de la ejercida por el Estado en la correspondiente Ley marco o básica.

\section{a') Seguridad Social y televisión}

¿Cuáles son esas parcelas o sectores de materias que, siendo de competencia exclusiva de la Generalitat, ésta no goza en relación con ellas de potestad legislativa? Por un lado, el régimen económico de la Seguridad Social, a propósito del cual al ente autonómico catalán solamente corresponde su gestión, tal como establece con meridiana claridad el número 2, en sus apartados $a$ ) y $b$ ), del artículo $17 \mathrm{del}$ Estatuto, ajustado estrictamente en este punto al artículo 149, 1, 17.a, de la Constitución. Por otro, el extraño y ciertamente original y pintoresco-por no emplear otros calificativos menos sùaves...-nú- 
mero 3 del artículo 16, que, en base a la Disposición transitoria octava, en su primer párrafo, queda totalmente vaciado de su posible virtualidad en lo que a la televisión dependiente de la Generalitat se refiere, ya que si la misma es otorgada "en régimen de concesión" por el Estado, reservándose éste su titularidad, parece evidente que la "regulación" a que se refiere el artículo 16,3 , no puede ser de naturaleza legislativa, sino exclusivamente de orden reglamentario interno, del referido servicio.

Dada la independencia que parece existir entre el número 1 y el 3 del artículo 16 del Estatuto-puesto que sólo al último se refiere la citada Disposición transitoria-podría entenderse que la potestad legislativa de la Generalitat-dictada en desarrollo de la básica del Estado en esta materia-concierne a la totalidad del régimen de radiodifusión, pero sólo parcialmente al de televisión, concretamente, al relativo a la eventual difusión de este medio audiovisual por particulares.

\section{b') Materias incluidas en el articulo 12 del Estatuto}

Por último, a la vista tanto de la fórmula con que se encabeza la redacción del artículo 12 ("De acuerdo con las bases y la ordenación de la actividad económica general y la política monetaria del Estado...") como con determinadas expresiones de los apartados incluidos en el número 1 del citado precepto, cabe preguntarse si la Generalitat puede ejercer en las materias o parcelas o sectores de las mismas a que aquél alude potestades legislativas, es decir, si puede dictar Leyes-en desarrollo de las correspondientes básicas del Estado-o si sólo ha de limitarse al ejercicio de potestades reglamentarias y/o simplemente ejecutivas. La respuesta no es, desde luego, nada fácil, ya que, por un lado, de haberse querido precisar que en tales casos corresponde a la Generalitat el "desarrollo legislativo y la ejecución" de la legislación básica estatal, se habría formulado el precepto de otra manera o se habrían incluido aquéllos en otros artículos, por ejemplo en el 10; y, por otro, se trata de materias-de naturaleza económica - en las que, normalmente, el Estado se reserva una intervención profunda con el fin de llevar a cabo una política económica unitaria dentro de su territorio (en general, sobre este tema me remito a un reciente y sugestivo trabajo de J. TORNOS).

Pues bien, dicha política económica estatal-general, monetaria o de precios, como precisa, según los supuestos, el artículo en 
cuestión-¿ha de realizarse exclusivamente por medio de Leyes o puede también ponerse en práctica mediante otras técnicas, por ejemplo, disposiciones de valor reglamentario, directrices, etc.?

No cabe duda que la formulación del artículo 12 del texto definitivo del Estatuto es mucho más matizada con respecto a la competencia exclusiva de la Generalitat de lo que lo era su homónimo del Proyecto aprobado por la Asamblea de Parlamentarios catalanes. Sin embargo, entiendo que tanto de la Constitución como del propio precepto estatutario cabe razonablemente deducir que la Generalitat puede ejercer en las materias enunciadas la potestad legislativa en el marco de la legislación básica que el Estado dicte al respecto. Con lo cual parece que debería excluirse-por contradictoria con la asunción de dicha potestad-la posibilidad de que el Estado (o mejor dicho, el Gobierno) pueda vincular a la Generalitat en tales materias mediante la emanación de Reglamentos o directrices.

\section{c') Breves conclusiones}

De cuanto llevamos dicho podría concluirse que tan exclusivas como las competencias atribuidas a la Generalitat en los artículos 9 y 12 son las contenidas en los artículos 10,16 y 17 . Y tanto en unos como en otros-excepción hecha de los supuestos mencionados y del que aludiré a continuación-la Generalitat tiene atribuidas potestades legislativas. El "desarrollo legislativo" a que se refieren los artículos 10, 16 y 17 del Estatuto es, pues, desarrollo por Ley aprobada por el Parlament de Catalunya de la legislación básica del Estado dictada en esas materias y no simplemente desarrollo reglamentario. Al igual, por otro lado, aunque no se diga de modo explícito, de lo que ocurre en los números 7,8 y 10 del artículo 9 .

\section{c) Supuestos de no coincidencia entre exclusividad de la competencia y potestad legislativa}

A diferencia de lo que establecía el artículo 24, 2, del Proyecto de Estatuto aprobado por la Asamblea de Parlamentarios, en el texto definitivo se ha introducido una salvedad de modo que no necesariamente en todos los casos de atribución de competencias exclusivas a la Generalitat ésta asume la totalidad de las funciones expresadas en el mismo y, en particular, por lo que ahora interesa, la potestad 
legislativa. "En el éjercicio de sus competencias exclusivas-dice ahora el artículo 25, 2-corresponderá a la Generalitat, según proceda, la potestad legislativa, la potestad reglamentaria y la función ejecutiva, incluida la inspección". Ambito de competencia exrlusiva y poder legislativo no son, pues, dos círculos que, superpı estos, coincidan plenamente. De acuerdo con el precepto transcrito puede existir el primero sin que forzosamente se dé el segundo. No per rece, sin embargo, que sean muchos los casos en que existe tal disociación en el Estatuto. En efecto, aparte de los ya señalados, por mi parte sólo he localizado otro, que puede, incluso, interpretarse de diversa manera. Se trata del supuesto previsto en el número 19 del artículo 9 del texto estatutario.

En dicho precepto se atribuye a la Generalitat competencia exclusiva en materia de "ordenación farmacéutica", haciendo a continuación la salvedad de que ello es así "sin perjuicio de lo dispuesto en el número 16 del apartado 1 del artículo 149 de la Constitución", que reserva al Estado como competencia exclusiva la "legislación de productos farmacéuticos", con carácter global y no sólo los aspectos básicos o de principio actualizables a través de la técnica de la Ley marco. Ahora bien, ¿"ordenación farmacéutica" y "legislación de productos farmacéuticos" son expresiones equivalentes e intercambiables? Si así fuera, habría que excluir de tal materia la potestad legislativa de la Generalitat. A otra conclusión cabría llegar, por el contrario, si de una interpretación combinada de los artículos 9, 19 y 17, 3, del propio Estatuto ("Corresponderá también a la Generalidad de Cataluña-dice el segundo de tales preceptos-la ejecución de la legislación del Estado sobre productos farmacéuticos"), se dedujera que no se trata de una pura y simple duplicidad, de modo que el último artículo se limitara a reiterar, de modo superfluo, lo ya dicho por el primero, sino que la "ordenación farmacéutica" es algo más que la regulación de los "productos farmacéuticos", por ejemplo, el régimen de establecimiento de industrias farmacéuticas (laboratorios) y de oficinas de farmacia. Si se admitiera esta interpretación, los preceptos citados no se solaparían entre sí, de modo que, aparte del sector específico dentro de la materia farmacéutica reservado a la entera potestad legislativa del Estado-el relativo a los "productos farmacéuticos"-, en el que la Generalitat sólo asumiría competencias de pura ejecución, en todo lo demás dicha Comunidad Autónoma tendría atribuida la potestad legislativa, no vinculada, por otro lado, a legislación básica previa del Estado. 
d) Enseñanza, policía y administración de justicia

Con las materias a que se ha hecho referencia no queda agotada la problemática relativa al ámbito de ejercicio de la potestad legislativa de la Generalitat. Al margen de aquéllas existen otras, contempladas en el Estatuto en preceptos especialmente concernientes a las mismas. Se trata de las polémicas materias de enseñanza, policía y administración de justicia. ¿Podrá la Generalitat regularlas mediante Leyes? En mi opinión, la respuesta debe ser positiva, aunque haya que matizar en orden a la determinación de la extensión concreta de tal poder legislativo.

Por lo que respecta a la primera de tales materias, el artículo 15 del Estatuto establece que "es de la competencia plena de la Generalidad la regulación y administración de la enseñanza en toda su extensión, niveles y grados, modalidades y especialidades, en el ámbito de sus competencias (sic), sin perjuicio de lo dispuesto en el artículo 27 de la Constitución y Leyes Orgánicas que, conforme al apartado 1 del artículo 81 de la misma, lo desarrollen, de las facultades que atribuye al Estado el número 30 del apartado 1 del artículo 149 de la Constitución y de la alta inspección necesaria para su cumplimiento y garantía".

Sabida es la tensión que hubo dentro y fuera del Congreso entre los grupos parlamentarios de uno y otro signo a propósito de la fórmula contenida en el artículo 15 del Proyecto de Estatuto, mucho más clara que la definitiva y, a mi modo de ver, ajustada al texto constitucional. Entre otras modificaciones de la redacción originaria de tal precepto, se ha sustituido la expresión competencia exclusiva por la de competencia plena. Ahora bien, ¿qué quiere decir competencia plena? ¿Algo de menor entidad que competencia exclusiva? ¿Se ha pretendido, acaso, tomar a préstamo un adjetivo que en el régimen de dedicación docente en los centros oficiales de enseñanza tiene un significado diferente al de "exclusivo"? El Estatuto no nos lo aclara. Se trata, sin duda, de un concepto "estatutariamente indeterminado", un concepto, por otro lado, insólito en el propio texto estatutario y para cuyo esclarecimiento de nada sirve acudir al Diccionario de la Real Academia Española. He aquí una más de las típicas expresiones sin un significado definido a que se aboca tantas veces en el compromiso político. ¿Pero jurídicamente significa algo diferente, en el contexto del propio Estatuto y sobre la base de la Constitución, que competencia exclusiva? A mi modo de ver, no. Tanto de uno como de otra se deducen las mismas consecuencias de 
cara a las competencias de la Generalitat en materia de enseñanza, con independencia de que la expresión utilizada sea la de competencia plena o la de competencia exclusiva.

En realidad, en el artículo 15 del Estatuto se contemplan dos supuestos. Por un lado, el relativo a "la regulación de las condiciones de obtención, expedición y homologación de títulos académicos y profesionales", que, de acuerdo con el artículo 149, 1, 30, de la Constitución, corresponde al Estado. Por otro, el concerniente al artículo 27 del mismo texto fundamental, en relación con el cual al Estado compete, con arreglo al precepto primeramente citado, dictar las "normas básicas" para el desarrollo del segundo. Correlativamente y, en consecuencia, a la Generalitat sólo le están atribuidas en el primer caso competencias de pura ejecución-dado que el Estado se reserva totalmente "la regulación" de dicho sector-, mientras que en el segundo la citada Comunidad Autónoma asume, además del poder reglamentario y de las funciones de simple ejecución, la potestad legislativa, bien que en desarrollo de la correspondiente legislación básica del Estado, que, en este último supuesto, ha de instrumentarse, además, en parte mediante Ley Orgánica. La "regulación" a la que alude el artículo 15 del Estatuto es, pues, regulación no sólo de rango reglamentario, sino también legislativo por parte de la Generalitat en lo que respecta al ámbito material del artículo 27 de la Constitución y en el marco de la correspondiente legislación estatal básica.

Por lo que se refiere a la Policía Autónoma, que, según el artículo 13 del Estatuto, podrá crear la Generalitat, entiendo que tal decisión corresponderá adoptarla al Parlament catalán mediante Ley. Y apoyo esta opinión en el sistema de relaciones existentes entre Ley y Reglamento de la citada Comunidad Autónoma-o, lo que es lo mismo desde una perspectiva organizativa, entre Parlament y Govern-, tal como se deducen del texto estatutario, punto éste que abordaré más adelante. Lo que ahora importa destacar es que se trataría, eso sí, de una Ley sin apenas otro contenido que el de plasmar-¿en un artículo único?-la decisión política parlamentaria de crear tal Policía Autónoma. Porque, por un lado, las funciones de la misma, o están ya establecidas en el propio Estatuto o se remiten por éste a la Ley Orgánica ex artículo 149, 1, 29, de la Constitución, y, por otro, corresponde a la "Junta de Seguridad"-formada por un número igual de representantes del Gobierno y de la Generalitat-, que se crea por el mismo texto estatutario, la determinación del "Estatuto, Reglamento, dotaciones, composición numérica y estruc- 
tura y el reclutamiento" de tal Policía. Aunque se trata de un órgano diferente de la "Comisión Mixta", regulado en la Disposición transitoria sexta del Estatuto y éste nada dice sobre la manera en que han de plasmarse jurídicamente las determinaciones de la Junta en cuestión en los aspectos reseñados, creo que puede aplicarse lo previsto expresamente a propósito de aquélla. Así, los acuerdos de la Junta de Seguridad habrán de adoptar la forma de propuesta al Gobierno, correspondiendo a éste su aprobación mediante Decreto, que deberá publicarse simultáneamente en el Boletín Oficial del Estado y en el Diari Oficial de la Generalitat.

Por último, por lo que concierne a la administración de justicia, entiendo que la Generalitat podrá ejercer la potestad legislativa tanto para organizar el Tribunal Superior de Justicia a que se refiere el artículo 19 del Estatuto, como para "fijar la delimitación de las demarcaciones territoriales de los órganos jurisdiccionales de Cataluña y la localización de su capitalidad" y "coadyuvar en la organización de los Tribunales consuetudinarios y tradicionales y en la instalación de los Juzgados, con sujeción en todo caso a lo dispuesto en la Ley Orgánica del Poder Judicial" (art. 18, 2. y $3 .^{9}$ ), bien entendido que en los distintos supuestos a que alude el último precepto cabe una amplia remisión normativa a la potestad reglamentaria del Govern de la Generalitat. Al margen de las hipótesis mencionadas, ninguna otra potestad normativa, ni siquiera la actualizable a través de disposiciones de rango reglamentario, corresponde en materia de administración de Justicia a dicha Comunidad Autónoma (vid. los arts. 20 a 23 del Estatuto, que se remiten reiteradamente a Leyes del Estado, orgánicas u ordinarias), lo que se explica, sin duda, por la configuración constitucional del Poder judicial como poder único en todo el ámbito del Estado (Martín ReBOllo).

\section{B) Materias de atribución extraestatutaria}

Aparte de. las materias en que con base en la Constitución y de acuerdo con el Estatuto, la Generalitat ostenta la potestad legislativa - con menor o mayor extensión según que el Estado tenga o no reservada la potestad de dictar la correspondiente normativa básica-, que hemos calificado como materias de competencia propia, institucional o estatutaria de tal ente autónomo, éste puede ver ampliada la esfera de ejercicio de dicha potestad a través de dos vías. Una, la del artículo 150, 1, de la Constitución, según el cual "las 
Cortes Generales, en materias de competencia estatal, podrán atribuir a todas o a alguna de las Comunidades Autónomas la facultad de dictar, para sí mismas, normas legislativas en el marco de los principios, bases y directrices fijados por una Ley estatal". Mediante esta técnica, la Generalitat puede, pues, ver extendida su potestad legislativa a materias distintas de aquéllas a las que nos hemos referido, con la única particularidad de que tal potestad deberá ejercerse en todo caso en desarrollo de la correspondiente normativa legal básica del Estado.

La otra vía es la prevista en el número 2 del mismo precepto constitucional, que dice así: "El Estado podrá transferir o delegar en las Comunidades Autónomas, mediante Ley orgánica, facultades correspondientes a materia de titularidad estatal que por su propia naturaleza sean susceptibles de transferencia o delegación". Pues bien, en el supuesto de que lo que se transfiera a la Generalitat sea la potestad legislativa sobre una materia, aquélla verá igualmente aumentado su ámbito normativo de ese rango, con un alcancé superior al del caso anterior, ya que, a diferencia de éste, en el que ahora contemplamos la Comunidad Autónoma no se limitará a desarrollar una Ley marco o básica del Estado. De ahí el reforzamiento que para realizar tal operación supone tanto la exigencia de una Ley orgánica como la exclusión de aquellas materias que "por su propia naturaleza" no sean susceptibles de transferencia. Cuáles sean éstas no nos lo dice la Constitución, pero por tales habrán de considerarse sin duda, entre otras, las siguientes: defensa, relaciones internacionales, régimen aduanero, sistema monetario y planificación general de la actividad económica (en cuanto a las bases y coordinación). Es decir, aquellas que incluso en los Estados de estructura federal se reserva la Federación.

A las dos vías señaladas alude expresamente el Estatuto de Catalunya en el artículo 28, en sus dos primeros apartados. "1. La Generalidad podrá solicitar del Estado la transferencia o delegación de competencias no asumidas en el presente Estatuto. 2. También podrá solicitar la Generalidad de las Cortes Generales que las Leyes marco que éstas aprueben en materia de competencia exclusiva del Estado atribuyan expresamente a la Generalidad la facultad de legislar en el desarrollo de dichas Leyes, en los términos del apartado 1 del artículo 150 de la Constitución”. En el tercero se atribuye "al Parlamento de Cataluña la competencia para formular las anteriores solicitudes y para determinar el Organismo de la Generalidad a cuyo favor se deberá atribuir en cada caso la competencia transferida o 
delegada". Pues bien, parece ocioso destacar que en el supuesto de asunción por parte de la Generalitat de potestades legislativas, el único Organismo habilitado para su ejercicio será el Parlament, sin perjuicio de la posibilidad de que en caso de transferencia propiamente tal (arts. 151, 2, de la Constitución y 28, 1, del Estatuto) dicha Asamblea autorice al Consell Executiu a dictar los respectivos Decretos legislativos con los requisitos establecidos en el artículo 33,1 , del Estatuto.

Bien entendido que en el supuesto de los artículos 150, 1, de la Constitución y 28, 2, del Estatuto el desarrollo legislativo de la correspondiente Ley marco estatal no puede corresponder más que al Parlament, a pesar del equívoco en que incurre el propio precepto constitucional, cuando al referirse al control de aquel desarrollo alude a la "competencia de los Tribunales", en general, dando a entender implícitamente que cabe una delegación legislativa de las Cortes Generales en los órganos de Gobierno de las Comunidades Autónomas, cuyo producto normativo en este caso, en la medida que se excediera de las bases, podrá ser inaplicado o incluso anulado por los Tribunales ordinarios. Equívoco cuya génesis parlamentaria ha explicado algún autor ( $\mathrm{MUNNOZ}$ MACHADO) ofreciendo argumentos que me parecen de peso en orden a cuestionar tal posibilidad, especialmente, el de que la propia Constitución en los artículos 82 y siguientes habilita exclusivamente al Gobierno del Estado para emanar Decretos legislativos (en materias, lógicamente, de la competencia de las Cortes Generales) (contra: EnTRENA).

Por otro lado, la confusión de técnicas que en base al equívoco en cuestión se contenía en el Anteproyecto de Estatuto elaborado por la llamada "Comisión de los veinte" ha desaparecido del texto estatutario definitivo. En efecto, en éste no queda ya ningún rastro de la mención que en aquél se hacía a los artículos 82 y 83 de la Constitución, cuando señalaba (art. 28, 2) que "la Generalitat podría también solicitar a las Cortes Generales que las Leyes marco y de bases que aprueben en materias de competencia exclusiva del Estado, atribuyan expresamente a la Generalitat de Catalunya la facultad de dictar la coirespondiente legislación delegada, en los términos de los artículos 82, 83 y 150, apartado 1, de la Constitución".

En conclusión, puede decirse que tanto del artículo 28, 2, del Estatuto como de una interpretación combinada y no contradictoria de los artículos 82, 83 y 150, 1, de la Constitución, ni aquél ni ésta permiten delegaciones legislativas de las Cortes Generales en el Consell Executiu de la Generalitat de Catalunya. 


\section{LIMITES}

Toda potestad, incluida la legislativa, tiene unos límites. Jurídicamente, al igual que no hay derechos ilimitados, tampoco existen potestades sin límites. Estas son inherentes al concepto de potestad. Pues bien, en un sistema constitucional como el vigente en el que la potestad legislativa no es monopolio del Estado, sino que también puede corresponder a otros entes, concretamente, a las Comunidades Autónomas, aparece como algo ineludible la delimitación de los respectivos ámbitos del poder legislativo. Tal delimitación se opera, al filo de la distribución de competencias entre unos y otros, en primer lugar, en la Constitución y, en segundo término, en los respectivos Estatutos de Autonomía.

Dichos límites pueden ser generales o específicos, según que afecten, respectivamente, a todas o sólo a algunas de las clases de Leyes que dicte una Comunidad Autónoma.

\section{A) Generales}

\section{a) Ratione materiae}

Dado el papel atribuido constitucionalmente al Estatuto de toda Comunidad Autónoma, me parece absolutamente redundante senalar que la Generalitat no podrá regular mediante Ley aquellas materias o sectores de éstas reservadas por la Constitución al Estado. Esto es algo obvio, dado que lo decisivo es el aspecto positivo de la cuestión: que la Generalitat sólo podrá dictar Leyes en aquellas materias o sectores en que el Estatuto o una Ley estatal al margen del mismo (art. 150, 1 y 2, de la Constitución) le haya atribudio la potestad legislativa. Tenemos así el primero de los límites de ejercicio de dicha potestad legislativa: el límite ratione materiae, sobre el cual no parece que sea necesario insistir demasiado a la vista de lo expuesto en el epígrafe anterior. Un par de observaciones, sin embargo, me parece oportuno hacer al respecto en este momento: una, que la potestad legislativa de la Generalitat puede ser afectada-y, por tanto, limitada-en cualquier materia por el ejercicio de sus competencias por parte del Estado en el ámbito de las relaciones internacionales y de la planificación económica (arts. 149, 3.a y 131, 1, de la Constitución); otra, que en relación con determinadas materias, el hecho de que estén reservadas a la Ley Orgánica no impide el desarrollo legislativo 
de ésta por parte de las Comunidades Autónomas y, en concreto, del ente autónomo catalán.

Que la planificación general, aprobada por Ley del Estado, limite la ordenación legislativa de aquellas materias o sectores de índole económica que sean de competencia de la Generalitat no parece que ofrezca especiales problemas, siempre que tal planificación estatal tenga como objetivos "atender a las necesidades colectivas, equilibrar y armonizar el desarrollo regional y sectorial y estimular el crecimiento de la renta y de la riqueza y su más justa distribución" (artículo 131, 1, de la Constitución). El propio artículo 12 del Estatuto-según vimos-establece claramente la vinculación de las competencias del ente autonómico catalán en una serie de materias a "las bases y la ordenación de la actividad económica general".

Mayores dificultades plantea, en cambio, la sujeción por parte de la Comunidad Autónoma catalana a la política internacional del Gobierno expresada a través de los correspondientes tratados o convenios. ¿Hasta qué punto pueden éstos, una vez convertidos en derecho interno, afectar a las competencias atribuidas a la Generalitat, y, en concreto, a las de índole legislativa? Pues bien, creo que sólo en el caso de que el convenio sea autorizado por las Cortes-no, en cambio, cuando éstas sean simplemente informadas de la conclusión de aquél-podrá vincular a dicha potestad legislativa, sin que, por lo demás, tal vinculación exceda de la sujeción a unas bases, marco o principios generales, sin llegar nunca a sustraer o vaciar de contenido la potestad en cuestión, ya que en este caso se produciría a través de un procedimiento distinto del previsto en la Constitución y en el propio Estatuto una modificación de éste, lo que, como es evidente, no es constitucionalmente posible. Aunque, a diferencia del Estatuto del País Vasco (art. 20, 3: "Ningún tratado o convenio podrá afectar a las atribuciones y competencias del País Vasco si no es mediante el procedimiento del artículo 152, 2, de la Constitución, salvo lo previsto en el artículo 93 de la misma"), no haya en el de Catalunya un precepto expreso en tal sentido, creo que basta con lo dispuesto con carácter general tanto en el texto constitucional (art. 152,2) como en el estatutario catalán (arts. 56 y 57) para llegar a la conclusión señalada.

Sólo en el supuesto del artículo 93 de la Constitución y a través del procedimiento previsto en el mismo ("Mediante Ley Orgánica se podrá autorizar la celebración de tratados por los que se atribuya a una organización o institución internacional el ejercicio de competencias derivadas de la Constitución") cabe limitar 'o, incluso, excluir 
competencias-y, entre ellas, las de orden legislativo-atribuidas estatutariamente a la Generalitat. Dicho ente no puede ser una excepción, aunque nada se diga a ese respecto en el Estatuto catalán, a diferencia del relativo al País Vasco que, como hemos visto, contiene expresamente dicha eventualidad. Y es que la posibilidad de tal desapoderamiento-que afecta por igual a todos los Poderes públicos-viene establecido con carácter general en el texto constitucional, que es la fuente primaria de cualesquiera potestades y competencias.

Por último, en relación también con el tema que estamos planteando contiene el Estatuto dos previsiones de distinto signo, en el artículo 27, apartados 3 y 5 . Según la primera, "la Generalidad de Cataluña adoptará las medidas necesarias para la ejecución de los tratados y convenios internacionales en lo que afecten a las materias atribuidas a su competencia, según el presente Estatuto". De acuerdo con el segundo, "la Generalidad será informada, en la elaboración de los tratados y convenios, así como de los proyectos de legislación aduanera, en cuanto afecten a materias de su específico interés". Se trata, en este último caso, de una cautela ciertamente importante, ya que aunque el Gobierno del Estado no tiene otro deber que el de informar a la Generalitat en tales supuestos, sin que quede en modo alguno vinculado por una eventual toma de postura por parte de tal Comunidad Autónoma, si deja de hacerlo la disposición adoptada estará viciada-faltaría un elemento esencial del procedimiento-y podrá anularse por inconstitucional. Por otro lado, para que la Generalitat haya de ser informada no es preciso que la materia objeto de regulación por los cauces aludidos sea de la competencia de aquélla; basta con que sea de "su específico interés", concepto éste, evidentemente, mucho más amplio.

Por lo que respecta a la segunda observación que quería hacer a propósito del límite que estamos considerando, debe notarse que contra lo que parece deducirse de una primera lectura del artículo 81 de la Constitución y del resto de preceptos que reservan a la Ley orgánica la regulación de determinadas materias, existen algunas de éstas cuya normativa a nivel legislativo no se agota utilizando aquella técnica. O dicho con otras palabras, que no necesariamente cuando una materia está reservada a la Ley orgánica (estatal, claro es) queda excluida la competencia legislativa de las Comunidades Autónomas. Ejemplos de este tipo nos lo ofrecen los artículos 10, 2; 13,$1 ; 15$ y $18,3 .{ }^{9}$, del. Estatuto, en conexión, respectivamente, con los artículos 92,$3 ; 149,1,29 .{ }^{\circ}$ y $30 .^{\circ}$, y 122,1 , de la Constitución. De 
acuerdo con el primero de aquéllos, "corresponde a la Generalidad el desarrollo legislativo del sistema de Consultas Populares Municipales en el ámbito de Cataluña, de conformidad con lo que dispongan las Leyes a que se refiere el apartado 3 del artículo $92 \ldots$ de la Constitución..."; el segundo habilita a la Generalitat a "crear una Policía Autónoma en el marco del presente Estatuto y, en aquello que no esté específicamente regulado en el mismo, en el de la Ley Orgánica prevista en el artículo 149, 1, 29., de la Constitución"; el tercero, concerniente a la polémica materia de la enseñanza, conecta las potestades del ente autónomo catalán-entre las cuales está la legislativa, como vimos antes-con la referencia al artículo 149, 1, 30.9, de la Constitución, en el que se reservan al Estado únicamente las "normas básicas para el desarrollo del artículo 27" de la misma; por último, el artículo 18, 3.9, del Estatuto dispone que corresponde a la Generalitat "coadyuvar en la organización de los Tribunales consuetudinarios y tradicionales y en la instalación de los Juzgados con sujeción en todo caso a lo dispuesto en la Ley Orgánica del Poder Judicial".

En todos los supuestos recogidos existe, pues, una compartición de potestades legislativas entre el Estado-que las actúa mediante Ley Orgánica-y la Generalitat de Catalunya, que ha de emanar la correspondiente Ley autonómica. Compartición que se articula en torno a la conocida división entre normas marco, básicas o de principio, por un lado, y normas de desarrollo de aquéllas, por otro.

\section{b) Ratione territorii}

Junto al límite ratione materiae, existen otros dos que, siguiendo la misma terminología, podríamos encuadrar bajo las expresiones ratione territorii y ratione temporis. De acuerdo con el primero, la eficacia de las Leyes se extiende, en principio, exclusivamente al territorio de Catalunya, que, con más "voluntad política" de lege ferenda que corrección jurídica-los entes citados a continuación en primer lugar no están aún constituidos-, viene definido en el artículo 2 del Estatuto como "el de las comarcas comprendidas en las provincias de Barcelona, Gerona, Lérida y Tarragona en el momento de promulgarse el presente Estatuto". En este sentido, el artículo 7, 1, del mismo texto-que concreta en el ámbito normativo el principio general sancionado en el artículo 25, l-señala que "las normas y disposiciones de la Generalidad y el Derecho civil de Cataluña 
tendrán eficacia territorial, sin perjuicio de las excepciones que puedan establecerse en cada materia y de las situaciones que hayan de regirse por el estatuto personal u otras normas de extraterritorialidad". Dichas excepciones se refieren, prácticamente, a los supuestos derivados del régimen de convenios intercomunitarios (art. 145, 2, de la Constitución y 27, 1 y 2, del Estatuto), del estatuto personal en materia de Derecho foral (arts. 149, 1, 8. ${ }^{2}$, de la Constitución y 13 y siguientes del Código Civil) y de la vecindad civil en el orden tributario (T. R. FERNÁNDEZ).

\section{c) Ratione temporis}

El tema que plantea el último de los límites mencionados es ni más ni menos que éste: ¿podrá ejercer la Generalitat las potestades legislativas atribuidas por el Estado tan pronto como se constituya el Parlament que resulte de las próximas elecciones? Tema, como podrá comprenderse, de una gran trascendencia y cuya solución exige, a mi modo de ver, una serie de matizaciones en función de los diversos supuestos, ya que no parece que pueda ofrecerse una respuesta tajante e indiscriminada en sentido afirmativo o negativo.

De acuerdo con esta premisa entiendo, frente a lo que ha manifestado recientemente algún autor (T.R. FERNANDEZ), que "la disponibilidad efectiva por las Comunidades Autónomas de las competencias que en cada materia recaben para ellas sus Estatutos" no "pasa necesariamente por un proceso previo de 'traspaso de los servicios correspondientes a los mismos' (art. 147, 1, d), de la Constitución)", $y$, en consecuencia, creo que "el efectivo ejercicio de la potestad legislativa regional" no necesariamente depende de la realización de tales traspasos.

Por lo que respecta, concretamente, a la Generalitat de Catalunya debe destacarse, en primer lugar, que en todas aquellas materias relativas a la organización de sus instituciones de autogobierno, conservación, modificación y desarrollo del Derecho civil catalán y normas procesales y de procedimiento administrativo que se deriven de las particularidades del Derecho sustantivo de Catalunya o de las especialidades de la organización de la Generalitat (es decir, los supuestos a los que se refiere el art. 9, en sus apartados 1 a 3, del Estatuto, que concretan la previsión de los arts. 148, 1, $1 .^{\mathrm{a}}$, y $149,1,6 .^{\mathrm{a}}$ y $8 .^{\mathrm{a}}$, de la Constitución), el Parlament podrá dictar 
las correspondientes Leyes-a las que, por lo demás, aluden de modo expreso los artículos $29,30,32,36,37,41$ y 42 del citado texto estatutario-tan pronto como lo desee.

Igualmente, una vez constituida la Asamblea legislativa catalana, podrá aprobar sin otros requisitos o condiciones ajenos a la misma las Leyes siguientes, previstas, asimismo, en el Estatuto: de creación de una Policía autónoma (art. 13), reguladora de las. elecciones al Parlament (art. 31), de organización y funcionamiento del "Sindic de greuges" (art. 35), aprobatoria del Presupuesto de la Generalitat (art. 49), acordando emitir Deuda pública (art. 51) y de la regulación de la administración, defensa y conservación del patrimonio de la Generalitat (art. 43). En cambio, la Ley sobre la organización del Tribunal Superior de Justicia deberá esperar a que se promulgue la Ley Orgánica del Poder Judicial (argumento deducido de lo dispuesto en los arts. 152, 1, 2. ${ }^{\circ}$, de la Constitución y 19 del Estatuto). Esta misma solución es de aplicación al ejercicio de la potestad legislativa por parte de la Generalitat en relación con los supuestos contemplados en los apartados $2 .{ }^{9}$ y $3 .{ }^{9}$ del artículo 18 del texto estatutario.

Es decir, en todas aquellas materias que no dependen de ningún traspaso por no estar, en realidad, con anterioridad a la publicación del Estatuto en el ámbito del Estado (la única excepción es aquí la regulación del Derecho civil a través del sistema actual de la "Compilación") o no tener que esperar a que se dicte una determinada Ley Orgánica, la potestad legislativa del Parlament puede actualizarse inmediatamente tras su constitución. La validez de esta conclusión no creo, por lo demás, que pueda ser razonablemente puesta en duda.

El problema-y la posible polémica-se plantea, naturalmente, en relación con el ejercicio de la potestad legislativa de la Generalitat en relación con aquellas materias que con anterioridad a la promulgación del texto estatutario eran de la competencia del Estado y que con dicho texto pasan a serlo del ente autónomo catalán. La pregunta que al respecto puede formularse es la siguiente: para actualizar dicha potestad ¿basta con la atribución de la correspondiente titularidad por el Estatuto o debe esperarse a que se realice previamente el oportuno traspaso?

La cuestión apuntada no es ni mucho menos baladí dado el sistema previsto en la Disposición transitoria sexta del citado Estatuto, en la que se establecen las "bases" para el "traspaso de los ser- 
vicios inherentes a las competencias" que corresponden a la Generalitat.

En efecto, en la mencionada Disposición transitoria se señala un plazo-dos años-, no para la realización efectiva de los traspasos-como pretendía el Proyecto aprobado por la Asamblea de Parlamentarios catalanes-, sino exclusivamente para la fijación por la Comisión Mixta Gobierno-Consell Executiu del "término en que habrá de completarse el traspaso de todos los servicios que corresponden a la Generalitat'. Puede, pues, ocurrir perfectamente que transcurran cuatro, seis o más años desde la promulgación del Estatuto antes "de que se produzca la transferencia completa de todos los servicios del Estado al ente autónomo catalán. ¿Quiere decirse con ello que mientras tales transferencias no se produzcan la Generalitat no podrá ejercer sus competencias-y, en concreto, en lo que ahora interesa, las de índole legislativa-en relación con las correspondientes materias?

La negación a la Generalitat de la facultad de actualizar sus competencias mientras no se efectúen los traspasos, podría apoyarse en dos órdenes de consideraciones. Por un lado, en el ejemplo de lo ocurrido en Italia a propósito de las Regiones de Estatuto ordinario. Por otro, en que tal solución puede parecer la más razonable desde el punto de vista organizativo: si no se ha traspasado el aparato burocrático (los servicios en sentido orgánico) ni los bienes, ni tampoco los medios financieros y la Administración del Estado va a seguir operando en la materia no traspasada, de acuerdo con las Leyes, Reglamentos, directrices e instrucciones de los órganos competentes-centrales y periféricos-, ¿de qué le sirve a la Generalitat dictar Leyes (y, en desarrollo de éstas, disposiciones de rango reglamentario)? Para nada, ya que no serían aplicables y no vincularían ni a los órganos estatales ni a los ciudadanos. Serían Leyes (y disposiciones normativas, en general) sin vigencia, sin ofectividad práctica; en definitiva, puro papel mojado-al menos, emporalmente-, que, si acaso, lo único que producirían sería zonfusión e inseguridad jurídica por la duda que suscitaría la po;ibilidad de su eventual aplicación.

Ahora bien, tales argumentos no me parecen decisivos. El prinero, porque no tiene en cuenta que el esquema regional ordinaio italiano no responde a los mismos principios que el diseñado sor nuestra Constitución en relación con las Comunidades Autóıomas y, en concreto, con las de autonomía plena o de primer gra- 
do, como es el supuesto de la Generalitat de Catalunya. Así, entre otros elementos diferenciadores que no es del caso aquí resaltar, debe tenerse en cuenta que en Italia la efectividad de la asunción de las competencias atribuidas a las Regiones no se produce en virtud de los respectivos Estatutos, sino de las Leyes aprobadas por el Parlamento italiano con posterioridad a aquéllos. Así lo dispone, en efecto, con toda claridad, la Disposición transitoria octava de la Constitución de 1947, al señalar que "Leggi della Repubblica regolano per ogni ramo della pubblica amministrazione il passaggio delle funzioni statali attribuite alle Regioni". Lo que se ha producido, como se sabe, con carácter general para todas las Regiones de Estatuto ordinario a través de Decretos legislativos en desarrollo de sendas Leyes de bases de 16 de mayo de 1970 y de 22 de julio de 1975. Es decir, que lo que tales disposiciones legislativas realizan, como precisa la citada Disposición transitoria de la Constitución, no es simplemente el traspaso de los servicios en sentido orgánico o de los bienes que con anterioridad estaban en manos del Estado, sino el traspaso de las mismas competencias o funciones.

En el sistema español, en cambio, las competencias atribuidas estatutariamente a las Comunidades Autónomas se asumen efectivamente por éstas en virtud de lo establecido en los respectivos Estatutos, de modo directo e inmediato. De ahí el sentido diverso que tienen los términos "competencias" y "servicios" en el apartado $d$ ) del artículo 147, 1, de la Constitución, según el cual, entre otras previsiones, los Estatutos de Autonomía deberán contener "las competencias asumidas dentro del marco establecido en la Constitución y las bases para el traspaso de los servicios correspondientes a las mismas". Precepto éste del que se deduce la no equivalencia entre uno y otro concepto. Así, competencia equivaldría a potestad o función, mientras que servicio sería lo mismo que órgano u organismo. Por otro lado, en nuestro Derecho se ha optado-por muy discutible y criticable que sea dicha opción (C.OsC.IILL'E. I.A)-por remitir a los propios Estatutos de las respertinats Commindades Autónomas la determinación de "las bases para el traspaso de los servicios correspondientes a las mismas". No será, pues, una disposición legislativa estatal aplicable a todos aquellos entescomo ha ocurrido en Italia-, sino el propio Estatuto el que establezca el mecanismo concreto para llevar a cabo tal operación.

Pues bien, el mecanismo ideado a tales efectos ha sido la creación de "Comisiones Mixtas" de representantes del Gobiemo del Estado y de la Comunidad Autónoma de que se trate. En el caso de 
Catalunya, en las Disposición transitoria sexta de su Estatuto de Autonomía, tras distinguir, al igual que la Constitución, entre "servicios" y "competencias"- "El traspaso de los servicios inherentes a las competencias que, según el presente Estatuto, corresponden a la Generalitat...", comienza diciendo tal Disposición-, se encomienda a la Comisión Mixta la misión de "inventariar los bienes y derechos del Estado que deban ser objeto de traspaso a la Generalitat, de concretar los servicios $e$ instituciones que deban traspasarse y de proceder a su adaptación, si es preciso, de los que pasen a la competencia de la Generalitat". Se da, en consecuencia, por descontado que la competencia ya está atribuida al ente autónomo catalán por el propio Estatuto y que lo que queda pendiente es el traspaso de los bienes y de la organización correspondiente.

De acuerdo con lo expuesto, la Generalitat podría ejercer sus competencias-y, en concreto, las de índole legislativa-en aquellas materias que le hayan sido atribuidas por el Estatuto, aunque los servicios (Ía organización) dispuestos para la intervención en las mismas continúen temporalmente-hasta la realización efectiva del traspaso correspondiente-en manos del Estado.

Que la organización y los medios materiales y financieros estén dentro de la esfera de un ente (la Administración del Estado) y la potestad normativa-y, más específicamente, la legislativa-corresponda a otro (la Generalitat), no implica necesariamente una contradicción. Como ejemplo de tal disociación puede aducirse lo ocurrido en buena parte de las transferencias preautonómicas.

La confusión a que antes se aludía como una de las consecuencias de la disociación apuntada, no parece posible si se niega - como debe negarse, en mi opinión-que el Estado pueda seguir dictando normas en materias atribuidas a la competencia (normativa) de una Comunidad Autónoma por su propio Estatuto que afecten al territorio de la misma. Así, no creo que hubiera inconveniente jurídico-ni práctico-alguno en reconocer a la Generalitat la posibilidad de dictar Leyes sobre materias atribuidas a su competencia legislativa por el Estatuto, aunque la organización administrativa concerniente a las mismas no hubiera sido aún traspasada. Tanto los funcionarios adscritos a dicha organización, como los ciudadanos españoles con residencia en Catalunya afectados por tales Leyes, quedarían vinculados a ellas.

La actualización de los poderes legislativos-y, en general, de los normativos-atribuidos por el Estatuo a la Generalitat no de- 
pende, pues, a mi manera de ver, de la realización efectiva de los "traspasos" de los correspondientes "servicios", ya que aquéllos no necesitan, a diferencia de éstos, una ulterior concreción por parte de la Comisión Mixta, a la que corresponde exclusivamente, como se ha dicho antes, "inventariar los bienes y derechos del Estado..., concretar los servicios e instituciones... y proceder a la adaptación, si es preciso, de los que pasen a la competencia de la Generalitat", misión que desembocará en los oportunos acuerdos que "adoptarán la forma de propuesta al Gobierno, que las aprobará mediante decreto, figurando aquéllos como anejos al mismo, y serán publicados simultáneamente en el Boletín Oficial del Estado y en el Diari Oficial de la Generalitat, adquiriendo vigencia a partir de esta publicación". Decreto que tiene como contenido y objeto exclusivamente la aprobación de los acuerdos de la Comisión Mixta y no la de llevar a cabo "transferencias de competencias".

Cuestión diferente de la planteada hasta ahora es la de la extensión de las potestades legislativas de la Generalitat. A este respecto habría que distinguir dos supuestos: uno, el relativo a aquellas materias-o sectores o parcelas de las mismas-en que la potestad legislativa del ente autónomo catalán no ha de ser desarrollo de la básica dictada por el Estado, y otro, el caso en que a éste corresponde emanar la legislación marco y a la Generalitat el desarrollo legislativo de la misma. En el primer caso no hay problema, aunque, como se ha notado, no se haya producido el traspaso del correspondiente servicio. En el segundo, independientemente de que se haya dado o no esta circunstancia, ¿habrá de esperar la Generalitat a que las Cortes Generales dicten la oportuna Ley marco, básica o de principio? Al tema se ha referido recientemente entre nosotros MUNOZ MACHADO, planteando, al mismo tiempo, las distintas alternativas posibles. Una de ellas, la preconizada, precisamente, por dicho autor, era la que se sancionaba en la Disposición transitoria segunda del Proyecto de Estatuto aprobado por la Asamblea de los Parlamentarios catalanes, que decía así: "En las materias en que corresponda a la Generalitat la competencia relativa al desarrollo de la legislación básica del Estado y mientras éste no la dicte de manera específica, las disposiciones legislativas de la Generalitat señalarán en una disposición final la parte de la legislación del Estado considerada como básica. Corresponde al Tribunal constitucional el conocimiento de los conflictos de competencia que puedan derivarse de la aplicación de esta disposición". Pues bien, fórmula tan clara y razonable ha sido sustituida cn la 
versión definitiva del Estatuto, tras la discusión en la Comisión Constitucional del Congreso, por otra de ambigua y defectuosa redacción, discutible desde un punto de vista técnico, difícilmente inteligible en una primera lectura y que, en realidad, contempla, a mi modo de ver, dos supuestos diferentes. En efecto, de acuérdo con la nueva Disposición transitoria segunda, "mientras las Cortes Generales no elaboren las Leyes a las que este Estatuto se refiere y el Parlamento de Cataluña legisle sobre las materias de su competencia, continuarán en vigor las actuales leyes y disposiciones del Estado que se refieren a dichas materias, sin perjuicio de que su desarrollo legislativo, en su caso, y su ejecución, se lleve a cabo por la Generalidad en los supuestos así previstos en este Estatuto".

Los dos supuestos contenidos en el precepto transcrito serían los siguientes: uno, que el Estado no dicte la legislación básica sobre una materia y la Generalitat tampoco apruebe la correspondiente Ley de desarrollo; otro, aunque el Estado se abstenga, el Parlament elabore dicha legislación. Pues bien, en el primer caso el Derecho estatal se aplicará en Catalunya en su integridad en la materia a que se refiera. Se trata de la aplicación del principio, sancionado en la Constitución (art. 149, 3) y recogido en el Estatuto (art. 26, 2), según el cual el Derecho estatal es supletorio del Derecho de las Comunidades Autónomas. Principio que tiene, obviamente, como finalidad evitar el vacío normativo que puede producirse en el proceso de sucesión de ordenamientos, a poco que se retrase el ejercicio de la potestad legislativa por parte de dichas Comunidades.

En el segundo supuesto, en cambio, hay un "desarrollo legislativo" por parte de la Generalitat. Lo que ocurre es que las Cortes Generales no han aprobado previamente la respectiva legislación básica. Con la fórmula contenida en la Disposición que estamos comentando no por ello queda congelada la potestad legislativa - compartida con el Estado-atribuida al ente autónomo catalán. Pero lo que no se dice-como se decía, por el contrario, en la versión anterior-es que la legislación estatal habrá de considerarse exclusivamente a tales efectos en sus aspectos básicos. Es más; ahora parece extenderse la vinculación no solamente a las leyes-en todo su detalle articulado, ya que no se hace salvedad alguna-, sino también a las disposiciones de rango reglamentario. Lo cual no me parece en absoluto ajustado al principio constitucional de respeto dé la autonomía de las Comunidades Autónomas, y, en concreto, de la Generalitat de Catalunya, que, de ese modo y por el mero hecho de no adoptarse por el Estado la pertinente legislación básica, puede verse 
literalmente anulada en el ejercicio de su potestad legislativa si ha de respetar íntegramente no sólo las Leyes estatales en todo su detalle, sino, además, los Reglamentos que las desarrollan. Más correcto me parece en este punto el Estatuto vasco que, aunque no se refiere a los principios básicos de la legislación estatal anterior como "módulo" exclusivo a tener en cuenta por el Parlamento de dicha Comunidad Autónoma, limita por lo menos dicha vinculación a las "leyes", sin mencionar las demás "disposiciones" (Disposición transitoria séptima, apartado 1).

No hace falta decir, por último, que aunque haya desaparecido de la versión definitiva del Estatuto la mención al Tribunal Constitucional en orden a la resolución de los conflictos que puedan derivarse de la aplicación de la mencionada Disposición transitoria, aquél es, naturalmente, el organismo competente a tales efectos.

\section{d) Otros limites derivados de determinados preceptos constitucionales}

Al margen de los límites señalados, las Leyes de la Generalitat han de respetar, como es obvio, con carácter general, tanto la Constitución como el propio Estatuto de Autonomía de Catalunya. Para garantizar tal respeto existe un mecanismo-el recurso de inconstitucionalidad-al que luego aludiremos. Lo que ahora importa destacar es que de la Constitución se derivan una serie de principios que muy especialmente afectan a la potestad legislativa de las Comunidades Autónomas y, por tanto, a la de la Generalitat. Principios que también pueden considerarse como otros tantos límites a dicha potestad. Se trata de los siguientes: solidaridad intercomunitaria (arts. 2 y 138, 1), prohibición de privilegios económicos y sociales (art. 138, 2), igualdad de derechos y obligaciones de todos los españoles en cualquier parte del territorio del Estado (art. 139, 1) y prohibición de adoptar medidas que obstaculicen la libre circulación de personas y bienes en todo el territorio español (artículo 139, 2). Límites sobre los que se ha pronunciado con un cierto detenimiento T. R. FERNÁNDEZ, al que me remito, añadiendo por mi parte que se trata de límites perfectamente razonables-si se interpretan sin excesos antiautonomistas-y característicos de cualquier Estado con estructura federal o regional. 


\section{B) Específicos}

Por lo que respecta a los límites específicos de la legislación de la Generalitat, debe distinguirse según que ésta tenga atribuida una competencia compartida-distribuida verticalmente con el Estadoo separada. No decimos en este segundo supuesto exclusiva, porque tal adjetivo es-como ya indicamos antes-aplicable igualmente al primero. Pues bien, siguiendo a MuNOZ MaChado-al que me remito por entero para mayores detalles en torno a la interesante problemática que el tema plantea-, a la legislación compartida de la Generalitat le afectará un límite que no es propio de la legislación separada: los principios sentados en la legislación marco o básica del Estado, principios que competirá al ente autónomo catalán desarrollar y concretar en relación con su propio ámbito territorial.

Por otro lado, como límite específico de la legislación que llamamos separada, cabe señalar el representado por "los principios necesarios para armonizar las disposiciones normativas de las Comunidades Autónomas... cuando así lo exija el interés general". Ahora bien, como la apreciación de esa necesidad corresponde a las Cortes Generales (Congreso y Senado), que han de adoptar al respecto la correspondiente Ley por mayoría absoluta de cada Cámara, puede concluirse que se trata de un límite eventual, es decir, operativo sólo en el caso de que dicha Ley de armonización llegue efectivamente a aprobarse con una mayoría aún más reforzada que la de las Leyes orgánicas.

\section{LA POTESTAD REGLAMENTARIA}

1. Su Planteamiento a Nivel

CONSTITUCIONAL Y ESTATUTARIO

Con mayor parquedad aún que a propósito de la Administración del Estado, la Constitución se refiere a la potestad reglamentaria de las Comunidades Autónomas. Parece como si el constituyente hubiese ignorado, una vez más, la importancia real del producto normativo derivado del ejercicio de dicha potestad, en este caso en el ámbito competencial de unos entes a los que se reconoce autonomía política. Y si tal autonomía, como ya notamos al principio, sólo se da si existe potestad de hacer Leyes, no por ello debe olvidarse la 
necesidad de que éstas sean completadas y desarrolladas mediante disposiciones reglamentarias.

En efecto, no existe en la Constitución una mención directa y expresa de la potestad reglamentaria a favor de las Comunidades Autónomas. Unicamente dos referencias-implícita, una; indirecta, otra-pueden encontrarse a tal respecto en la citada Carta fundamental. La primera en el artículo 152, al aludir a las "funciones ejecutivas y administrativas" del Consejo de Gobierno; la segunda, en el artículo 153, que trata del control de la actividad de los órganos de dichas Comunidades, en cuyo apartado $c$ ) se atribủye a la jurisdicción contencioso-administrativa "el de la administración autónoma y sus normas reglamentarias".

Bien entendido que si la referencia del artículo 152 puede interpretarse en el sentido de que la potestad reglamentaria es inherente a la función ejecutiva-y así se ha venido entendiendo en nuestra historia constitucional con respecto al Gobierno y, en general, a la Administración del Estado (S. Martín-Rerortillo)-, no debe olvidarse que la misma se hace exclusivamente en relación con la organización de aquellas Comunidades Autónomas cuyos Estatutos se aprueben por el procedimiento del artículo 151. Como éste es el caso de Catalunya no vamos a insistir más en la cuestión, aunque creemos que, al igual que ocurre con la potestad legislativa, del hecho de que la Constitución no aluda a las demás Comunidades Autónomas no puede deducirse la inexistencia a favor de las mismas de potestad reglamentaria, especialmente, y aparte de razones de orden institucional-¿dónde estaría, entonces, la autonomía?-, a la vista de la formulación general, sin distinguir el tipo de Comunidad, contenida en el artículo $153, c$ ), del texto constitucional.

Pues bien, la misma parquedad que hemos encontrado en la Constitución con relación al tratamiento de la potestad reglamentaria de las Comunidades Autónomas en general es predicable del Estatuto de Catalunya a propósito de la Generalitat. Un par de preceptos también, en términos similares a los de la Carta fundamental y con idéntica referencia-implícita e indirecta, respectivamente-al tema que nos ocupa. La primera se contiene en el enunciado del artículo 37, l: "El Consejo, órgano colegiado de Gobierno con funciones ejecutivas y administrativas...". La segunda se halla en el apartado 4 del mismo precepto ("Todas las normas, disposiciones y actos emanados del Consejo Ejecutivo o Gobierno y de la Administración de la Generalidad que lo requieran serán 
publicados en el Diari Oficial de la Generalitat...") y en el artículo 40, 2 ("Contra los actos y acuerdos y las normas reglamentarias emanadas de los órganos ejecutivos y administrativos de la Generalidad, se podrá presentar recurso ante la jurisdicción contenciosoadministrativa.

Aunque de una manera implícita e indirecta, tanto de la Constitución como del Estatuto de Autonomía de Catalunya cabe deducir, pues, el reconocimiento a favor de la Generalitat de la potestad reglamentaria. Sentada esta premisa, veamos a continuación algunas de las principales cuestiones que se plantean en torno a tal potestad: órganos titulares, ámbito materiảl, relaciones entre Leyes y Reglamentos del ente autónomo catalán y límites al ejercicio de aquélla.

\section{Titularidad}

¿A qué órganos de la Generalitat corresponde la potestad reglamentaria? Algunos autores (Cosculluela, Muñoz Machado y BasSOLS), partiendo de la base de que el principio de división de poderes no se da, a diferencia de lo que sucede en el ámbito estatal en sentido estricto, en el marco de la Región-y ahora en el de las.Comunidades Autónomas-, entienden que no habría inconveniente en que la potestad reglamentaria de tales entes estuviera atribuida al mismo órgano que ostenta la potestad legislativa: al Parlamlento o Asamblea regional. Y ponen como ejemplo lo que ocurre en el sistema italiano en relación con las Regiones de estatuto ordinario.

Dicha tesis fue recogida en parte por el Anteproyecto de Estatuto elaborado por la "Comisión de los veinte", en cuyo artículo 33, 2, se establecía que "el Parlament podrá reclamar la competencia para la elaboración y aprobación de reglamentos generales de leyes estatales, de acuerdo con lo que dispone el artículo 28 de este Estatuto". Junto a esta previsión, el apartado 3 dal mismo precepto señalaba que "el Consell Executiu o Govern podrá elaborar reglamentos generales de las leyes de la Generalitat, cuando éstos lo hayan previsto expresamente y en los términos por ellos establecidos".

Más que en el esquema de distribución de poderes normativos entre los órganos de las Corporacione's locales-al que apelan los autores citados, como más próximo al de las Regiones que el del Estado-o en el de las mismas Regiones ordinarias italianas, creo que la Comisión citada se inspiró al redactar los preceptos transcritos en la ideología que, como se sabe, inspira el sistema anglosajón que, a 
partir de la desconfianza en el Ejecutivo, concentra, en principio, todo el poder normativo en el Parlamento, sin perjuicio de que luego éste de modo expreso delegue-con carácter recepticio o simplemente reglamentario-en el Gobierno el ejercicio de aquél. La acogida de dicho sistema-incoherente en un contexto en el que dominan las características propias del continental de raíz francesa-tenía, por lo demás, un defecto de gran relevancia en el Anteproyecto catalán. Y es que mientras que las Leyes aprobadas por el Parlament eran controladas por el Tribunal Constitucional y los Reglamentos y actos del Consell y, en general, de los órganos administrativos de la Generalitat eran recurribles ante los Tribunales contenciosos (art. 40), nada se preveía al respecto en relación con los Reglamentos aprobados por la citada Asamblea legislativa. ¿Quedaban exentos, pues, de todo control o, al menos, de un control jurisdiccional? (Cabría pensar, aunque no lo decía el Anteproyecto, que las Cortes Generales al autorizar al Parlament a dictar el correspondiente Rcglamento de una Ley aprobada por las mismas podrían reservarse algún tipo de control sobre la correcta utilisación de dicha potestad reglamentaria o encumiendárselo, incluso, al Gobierno). Que el control jurisdiccional quedaba excluido me parece evidente, ya que en cuanto Reglamentos no podían impugnarse ante el Tribunal Constitucional y por proceder de un órgano que no formaba parte de la Administración tampoco tenían acceso a la justicia contenciosa.

Pues bien, si se tiene en cuenta, por un lado, que las Comunidades Autónomas-y, especialmente, las de autonomía plena o de primer grado, como es el caso de Catalunya-son entes con autonomía política y no sólo ni exclusivamente Administraciones públicas como las Corporaciones locales; por otro, que el modelo configurado a propósito de aquéllas en la Constitución española de 1978 no coincide con el diseñado en relación con las Regiones en la Constitución italiana y, por último, que el sistema anglosajón es difícilmente asimilable en un contexto tan diferente cual el de nuestro país, podrá concluirse que tanto las posturas doctrinales antes aludidas como la mencionada redacción del Anteproyecto de Estatuto catalán no son sin más aceptables.

De ahí que me parezca plenamente acertada la rectificación operada en el punto que estamos tratando por el Proyecto de Estatuto aprobado por la Asamblea de parlamentarios, con el que viene a coincidir, por lo demás, el texto definitivo del mismo. En uno y otro desparecerá, en efecto, toda referencia a la'potestad reglamentaria del Parlament. Lo que ocurre es que ahora falta-como ya hemos 
señalado-una previsión expresa de la atribución de la potestad reglamentaria en el Consell Executiu o en cualquier otro órgano de la Administración autonómica catalana.

Pues bien, dicha falta de previsión no creo que sea relevante, dado que, en mi opinión, tal potestad debe entenderse incluida entre las "funciones ejecutivas" del Consell (arts. 152, 1, de la Constitución y 37, l, del Estatuto de Catalunya). El Consell Executiu sería, pues, el titular de la potestad reglamentaria de la Generalitat. Titularidad que ha de considerarse-al igual de lo que ocurre en el ámbito estatal con el Gobierno-exclusiva y excluyente con respecto a otros órganos administrativos del citado ente autónomo en el marco de la regulación de las relaciones generales de supremacía-sujeción. A los Ministros o Consellers y, en general, a los demás órganos de la Administración de la Generalitat les corresponderá-si así se establece en una Ley aprobada por el Parlament-una potestad reglamentaria limitada al ámbito interno, organizativo, doméstico o de las relaciones especiales de supremacía-sujeción.

Las razones en las que se apoya la delimitación a que acabamos de aludir son, en mi opinión, del mismo tenor que las que abonan la distribución de la potestad reglamentaria en la esfera estatal entre el Gobierno y los demás órganos administrativos. De ahí que no me parezca necesario explicitarlas en este momento, remitiéndome por entero a la doctrina que las recoge (vid., por todos, E. GARCIA DE ENterria, T. R. Fernández, J. L. Carro y R. Gómez-Ferrer).

Al margen del tema planteado, en cuanto que el órgano al que vamos a aludir no forma parte de la Generalitat, sino que, por estar integrado paritariamente por representantes de ésta y del Gobierno del Estado, se sitúa, en realidad, fuera de ambos entes, debe consignarse que la Junta de Seguridad, cuya creación se prevé en el artículo 13 del Estatuto vigente sobre el modelo del de 1932, tiene encomendada una importante potestad reglamentaria-bien que de natuleza organizativa-, en la medida en que le corresponde determinar "el Estatuto, Reglamento, dotaciones, composición numérica y estructura (y) el reclutamiento de la Policía de la Generalidad" (apartado 7 del precepto citado). Una potestad reglamentaria que, sin embargo, no podrá, seguramente, ejercer dicha Junta directamente, sino a través de la oportuna propuesta-que debe entenderse vinculante-al Gobierno del Estado, al que competerá aprobarla formalmente mediante Decreto. En definitiva, estaríamos en presencia de un mecanismo análogo al de los acuerdos adoptados por la 'Comisión 
Mixta de traspasos, a la que se refiere la Disposición transitoria sexta del Estatuto.

\section{3. Амвіто}

Al igual que en el supuesto de la potestad legislativa de la Generalitat, para saber en qué ámbito puede operar la potestad reglamentaria de la misma debe acudirse al Estałuto y, en concreto, al sistema de distribución de competencias entre el Estado y el ente autónomo catalán.

Ahora bien, no basta con que una materia esté atribuida a la Generalitat para que ésta pueda ejercer en relación con la misma la potestad reglamentaria. Así se desprende, en efecto, del por lo demás confuso enunciado del artículo 25, 2, del texto estatutario catalán, según el cual, tras indicar que "en el ejercicio de sus competencias exclusivas corresponde a la Generalidad, según proceda, la potestad legislativa, la potestad reglamentaria y la función ejecutiva, incluida la inspección" - a cuya problemática me he referido anteriormente-añade que "en el caso de las materias señaladas en el artículo 11 de este Estatuto, o con el mismo carácter en otros preceptos del mismo, su ejercicio deberá sujetarse a las normas reglamentarias que en desarrollo de su legislación dicte el Estado".

Del precepto transcrito cabe deducir, en base a una interpretación combinada de sus dos párrafos, lo siguiente: primero, que cuando la Generalitat tenga atribuida en relación con una materia la potestad legislativa-ya sea plena o de desarrollo de una Ley marco o básica del Estado-le corresponde igualmente la potestad reglamentaria; segundo, que dicho ente puede no disponer de potestad legislativa y sí, en cambio, de potestad reglamentaria, y tercero, que si la competencia asumida por la Generalitat es de "ejecución", debe entenderse excluida la potestad reglamentaria de su parte.

Dejando.al margen el primer supuesto, por no ofrecer problema alguno y remitiendo la consideración del segundo para más adelante, centrémonos en este mornento en el examen del último.

Pues bien, si se tiene en cuenta que tanto el citado artículo 11 como otros del mismo Estatuto atribuyen solamente a la Generalitat en determinadas materias "la ejecución de la legislación del Estado", la sumisión a las normas reglamentarias que éste dicte excluye en 
tales materias la potestad reglamentaria de la Generalitat. Conclusión que puede considerarse acertada si se piensa que el párrafo segundo del artículo 25, 2, del texto definitivo del Estatuto ha venido a sustituir al contenido del número 3 del artículo 24 del Proyecto aprobado por la Asamblea de parlamentarios, que rezaba así: "Las competencias de ejecución de la Generalidad comportan en todo caso la potestad reglamentaria y la administración, incluida la inspección". La sustitución de este texto por otro mucho más restrictivo de las facultades de la Generalitat debe interpretarse como una decidida voluntad de excluir el ejerciçio de la potestad reglamentaria de aquélla en las materias en las que corresponde al Estado la potestad legislativa plenaria (y no sólo la de dictar Leyes marco o básicas). La ejecución en el ámbito competencial de la Generalitat de Catalunya no tendría, por consiguiente, el significado ambivalente-ejercicio de la potestad reglamentaria y actividad de gestión en sentido estricto-que asumía dicho término cuando se conectaba en nuestros textos históricos constitucionales a la función del Gobierno. Bien entendido que, a diferencia de lo que establecía la Constitución de 1931 (art. 20, 2: "El Gobierno de la República podrá dictar Reglamentos para la ejecución de sus Leyes, aun en los casos en que esta ejecución corresponda a las autoridades regionales"), en la vigente ninguna salvedad se ha hecho al respecto de modo expreso.

No obstante, debe reconocerse que si se repasan atentamente los. distintos apartados del artículo 149, 1, de la Constitución en los que se reserva al Estado formalmente la "legislación" de determinadas materias-mercantil, penal y penitenciaria, procesal, laboral, civil, propiedad intelectual e industrial, pesas y medidas, productos farmacéuticos, expropiación forzosa, aprovechamientos hidráulicos cuando las aguas discurran por más de una Comunidad Autónoma-, se verá que, en unos casos, se trata de materias en las que el Estado, salvo habilitación legal expresa y específica, tampoco ha gozado hasta ahora de potestad reglamentaria-las referidas al orden penal, procesal o, en general, a las relaciones inter privatos-, en otros hay una remisión parcial a la competencia, incluida inupicitamente lid legislativa, de las Comunidades Autónomas-legislación procesal y civil-y, por último, en algún supuesto la expresión legislación se completa con la de "ordenación", que, obviamente, por ser más amplia, incluye a favor del Estado la potestad reglamentaria-aprovechamientos hidráulicos en la hipótesis citada-. De modo que, prácticamente, sólo en aquellas menciones relativas a las pesas y medidas, a los productos farmacéuticos y a la expropiación forzosa 
podría admitirse, en principio, la posibilidad de que dichas Comunidades ejercieran la potestad reglamentaria.

Curiosamente, en relación con una de estas últimas-la expropiación forzosa-la Generalitat no sólo goza de potestad reglamentaria, ya que el Estatuto-en mi opinión, inconstitucional en este puntole ha atribuido el "desarrollo legislativo" "en el marco de la legislación básica del Estado".

Quedarían, pues, sólo dos materias-pesas y medidas y productos farmacéuticos-, en las que, de acuerdo con la Constitución, la Generalitat podria haber asumido en el Estatuto la potestad reglamentaria sobre las mismas. No ha sido así según el texto estatutario (artículos 11, 5, y 17, 3) y no creo que haya que lamentarlo, habida cuenta de la trascendencia general-y no reducida al ámbito de cada Comunidad Autónoma-que la regulación de tales materias presenta.

Por lo demás, la inclusión del resto de materias no mencionadas hasta ahora y a las que se refiere el artículo 11 del Estatuto entre las competencias de mera ejecución de la Generalitat-excluida, pues, la potestad reglamentaria-por aplicación de lo señalado en el artículo 25, 2, del mismo texto, no parece que pueda discutirse si se tiene en cuenta que, en principio, podrían haber quedado enteramente reservadas al Estado. Con una excepción solamente (no lo es, en cambio, la limitación de la competencia de la Generalitat a la mera gestión en relación con el régimen económico de la Seguridad Social-artículo $17,2, b]$, del Estatuto-, ya que tal limitación halla su base en el artículo $149,1,17 .^{a}$, de la Constitución): la contenida en el número 9 del citado artículo 11 , cuya formulación, además, no deja de ser un tanto ambigua y contradictoria. Ya que, a pesar del encabezamiento del precepto en cuestión- "Corresponde a la Generalidad la ejecución de la legislación del Estado en las siguientes materias"-, se habla de "ordenación" (del transporte), expresión ésta que parece incluye la reglamentación del mismo. Más aún si se piensa que el supuesto a que se refiere es el típico de un servicio público de titularidad de la Generalitat-art. 9, 15, del Estatuto-, que, en consecuencia, podrá reglamentarlo enteramente, no entendiéndose muy bien qué quiere decirse con la salvedad final ("sin perjuicio de la ejecución directa que se reserve el Estado").

Lo que se ha dicho a propósito de la exclusión de la potestad reglamentaria de la Generalitat en aquellas materias en las que solamente tiene atribuidas funciones de ejecución ha de matizarse. 
sin embargo, en mi opinión, de la siguiente manera: que dicha exclusión debe entenderse en cuanto a la emanación de disposiciones reguladoras de relaciones generales de supremacía-sujeción, no, en cambio, de aquellas concernientes a la organización interna de los servicios cuya gestión tiene encomendado el ente autónomo catalán. $\mathrm{Y}$ es que, en efecto, la potestad reglamentaria limitada al aspecto exclusivamente organizatorio, interno o doméstico del servicio de que se trate, puede considerarse como una facultad inherente a la función de gestión o ejecución del mismo. Y ello aunque en el Estatuto de Catalunya, a diferencia del del País Vasco (art. 20, 4: "Las funciones de ejecución que este Estatuto atribuye a la Comunidad Autónoma del País Vasco en aquellas materias que no sean de su competencia exclusiva, comprende la potestad de administración, así como, en su caso, la de dictar reglamentos internos de organización de los servicios correspondientes") no exista una previsión expresa en tal sentido.

Por último, y al margen ya de lu previsto en el respectivo Estatuto, es posible que las Comunidades Autónomas y, en concreto, la Generalitat, asuman la potestad reglamentaria en relación con materias de titularidad estatal por la vía de la Ley orgánica prevista en el artículo 150, 2, de la Constitución. Si el Estado puede en base a dicho precepto transferir incluso la potestad legislativa cabe pensar que podrá también hacer lo menos: reservarse aquélla y transferir solamente la potestad reglamentaria. En este caso se estaría en presencia de la hipótesis antes mencionada, según la cual la Generalitat, sin disponer de potestad legislativa sobre una materia, puede, en cambio, tener encomendada la potestad reglamentaria (externa), siempre que la misma le sea atribuida extraestatutariamente.

\section{LIMITES}

En principio, mutatis mutandis, me parecen trasladables a la potestad reglamentaria de la Generalitat los límites-tanto generales como específicos, según los casos-propios de la potestad legislativa de la misma. No vamos, por ello, a repetir ahora de nuevo lo ya expuesto anteriormente a ese propósito.

Lo que en este momento importa destacar son los límites característicos de la potestad reglamentaria, que, de acuerdo con la ya tradicional distinción, pueden clasificarse en formales y sustanciales, 
incluyendo en la primera categoría la competencia, la jerarquía y el procedimiento, y en la segunda, los principios generales del Derecho -y entre ellos el de la irretroactividad, sancionado expresamente en la Constitución en el artículo 9, 3-y la materia reglamentaria. No añadimos a estos últimos-como ha solido hacerse por algún sector de la doctrina-las materias reservadas a la Ley, por las razones que expondremos más adelante al tratar el tema de las relaciones LeyReglamento de la Generalitat.

Sobre la competencia me remito a lo dicho al tratar el tema de la titularidad de la potestad reglamentaria de la Generalitat. Para mayores precisiones sobre este punto habrá que esperar a la Ley que sobre régimen jurídico de la Administración de aquélla dicte, en desarrollo de la correspondiente Ley básica del Estado, el Parlament catalán (arts. 149, 1, 18. ${ }^{a}$, de la Constitución y 10, 1, del Estatuto).

Desde la perspectiva de la jerarquía normativa, es de notar que si la sumisión de los Reglamentos de la Generalitat es incondicionada respecto de la Constitución, del Estatuto de Autonomía de Catalunya y de las Leyes y Decretos legislativos aprobados, respectivamente, por el Parlament y el Consell Executiu, tal sujeción sólo opera en relación con las Leyes emanadas de las Cortes Gunerales cuando éstas establecen el marco o los principios básicos en una materia en la guc al ente autónomo catalán compete el desarrollo legislativo-y, por consiguiente, reglamentario-o los principios de armonización a los que alude el artículo 150, 3, de la Constitución. No cualquier Ley del Estado vincula, pues, el ejercicio de la potestad reglamentaria de la Generalitat, sino sólo las del tipo señalado. Y ello porque, como es sabido, entre entes distintos-en este caso, el Estado y una Comunidad Autónoma-no juega el principio de jerarquía, sino el de competencia. Principio este último que más que cl primero podri:ı explicar incluso la vinculación de los Reglamentos-y de las Leyesde la Generalitat a las dos clases de Leyes estatales mencionadas.

Por otro lado, el principio de jerarquía actúa plenamente entre Reglamentos dictados por la Administración de la Generalitat en función del nivel de los órganos de los que proceden. En csle scintido, queda remitida a la Ley del Parlament antes aludida la sanción de un precepto análogo al que, en relación con la Administración estatal, existe ahora en la Ley de Régimen Jurídico (art. 23).

Lo mismo cabría decir a propósito del procedimiento, con idéntica remisión a la futura Ley del Parlament. Con dos precisiones solamente: una, que dicha Ley ha de regular necesariamente, de 
acuerdo con el principio general sancionado en el artículo 105, a), de la Constitución, "la audiencia de los ciudadanos, directamente o a través de las organizaciones y asociaciones reconocidas por la Ley, en el procedimiento de elaboración de las disposiciones administrativas que les afecten"; y otra, que las normas reglamentarias de la Administración autónoma catalana-al igual que los actos que lo requieran-habrán de publicarse para que sean válidas y eficaces en el Diari Oficial de la Generalitat (art. 37, 4, del Estatuto, el cual añade que "en relación con la publicación en el Boletin Oficial del Estado se estará a lo que disponga la correspondiente norma del Estado"').

En cuanto a los límites sustanciales, nada específico podemos decir acerca de los principios generales del Derecho; por lo que se refiere, en cambio, a la materia reglamentaria, debe recordarse, por un lado, lo señalado anteriormente sobre el ámbito de la potestad normativa de la Generalitat en tal nivel ordinamental y, por otro, lo que exponemos a continuación.

\section{Rel.ACiONES entre Ley y R F.GLAMENTO}

Tanto de la Constitución como del propio Estatuto de Catalunya se deduce claramente el principio de primacía de la Ley sobre el Reglamento de la Generalitat, que es la consecuencia en el plano jurídico de la consagración en el plano político de la prevalencia de la Asamblea Legislativa (Parlament) sobre el Consejo de Gobierno (el Consell Executiu o Govern).

En efecto, la Carta fundamental (art. 152, 1) y el texto estatutario (artículo 37) atribuyen al citauo órgano de gobierno "funciones ejecutivas y administrativas", mientras que el segundo (art. 30, 1) deja firmemente sentado que el Parlamento "representa al pueblo de Cataluña, ejerce la potestad legislativa e impulsa y controla la acción política y de gobierno". Se sanciona, pues, el "principio parlamentario" en el ámbito, naturalmente, de las competencias propias del ente autónomo catalán.

Las consecuencias que de uno y otro principio se deducen en orden a las relaciones Ley-Reglamento de la Generalitat son, como bien se comprenderá, de una gran trascendencia (las mismas que, servata distantia, se dan en la esfera estatal entre ambos tipos de manifestaciones normativas). En este sentido, debe proclamarse, con 
todo énfasis, que los Reglamentos de la Generalitat no sólo no pueden ir contra las Leyes aprobadas por la misma, sino que ni siquiera pueden dictarse al margen y con independencia de una Ley previa.

Esto es evidente en aquellos casos en que la Generalitat asume el "desarrollo legislativo" de la legislación básica dèl Estado. Sin una Ley previa del Parlament (o, al menos, un Decreto legislativo del Consell Executiu dictado en base al art. 33 del Estatuto) la Administración del ente autónomo catalán, ni siquiera el citado Consell, pueden emanar Reglamento alguno en la materia a que tal desarrollo legislativo se refiera. Entre la Ley marco estatal y el Reglamento autonómico ha de interponerse, pues, necesariamente, una Ley de la propia Generalitat.

Pero también en aquellas materias o sectores de éstas que según el Estatuto están reservadas a la competencia de dicha Comunidad Autónoma sin intervención legislativa previa del Estado-a salvo siempre, como ya sabemos, de la técnica del artículo 150,3, de la Constitución-debe llegarse a la misma conclusión. Y ello con independencia de que el Estatuto se remita o no explícitamente en tales casos a la Ley. Existen, desde luego, una serie de preceptos que lo hacen (así, los artículos 5,$3 ; 29,2 ; 30,1$ y $3 ; 32,6 ; 36,5 ; 37 ; 41 ; 42$; 43,$2 ; 48,2$; Disposición transitoria cuarta; e, ímplícitamente, los artículos 49, 50 y $5 \mathrm{l}$ ). Preceptos que no deben entenderse como otras tantas "reservas a la Ley", sino como simples concreciones o especificaciones del principio parlamentario o de supremacía de la Ley. Por consiguiente, aun en ausencia de tales remisiones específicas a la Ley, ha de estimarse que el Reglamento de la Generalitat no puede operar si no existe previamente una Ley que regule, siquiera sea mínimamente, la materia o sector de que se trate.

No caben, en efecto, en mi opinión, Reglamentos independientes, en ninguna materia, ni siquiera en la organizativa o interna de la Administración, ni en el ámbito estatal, ni en el de las Comunidades Autónomas y, en concreto, en el de la Generalitat de Catalumya. En tal esfera organizativa el margen para el ejercicio de la potestad reglamentaria será, desde luego, mayor que en el marco de las relaciones generales de supremacía-sujeción, pero no existe una desvinculación completa de la Ley. Esta ha de decir la primera palabra porque la Administración-tanto la del Estado como la de las Comunidades Autónomas-es Poder ejecutivo y no Poder exento de la Ley en ningún caso.

De ahí que en un sistema como el que se deriva lamto de nuestra 
vigente Carta fundamental como del Estatuto de Catalunya no tenga sentido hablar de "materias reservadas a la Ley"-a diferencia de lo que ocurre, en cambio, en una estructura constitucional basada en el "principio monárquico" (D. JESCH)-, ya que si la Ley ha de regular, aunque sea mínimamente, todas las materias, ¿por qué hablar, entonces, de "reserva" sólo en relación con algunas?

Sentadas las premisas anteriores, los Reglamentos de la Generalitat desarrollarán en todo caso lo dispuesto en Leyes anteriores de la misma. Lo que sucederá es que la vinculación de aquéllos con éstas será más estrecha o más laxa o, lo que es lo mismo, más puntual o más principial, según que la materia a que se refieran sea la propia, respectivamente, de las relaciones generales de supremacía-sujeción Administración-ciudadanos o de la organización interna, doméstica o de las relaciones especiales. Llevada esta conclusión al plano de las categorías de Reglamentos, podría decirse que si ya no existen los independientes, todos serían ejecutivos: unos "más" y otros "menos", pero todos dictados en ejecución o desarrollo de una Ley previa.

Sólo una excepción-relativa, como vamos a ver-cabe admitir a lo que se ha expuesto. Se trata de los Reglamentos que dicte la Generalitat en virtud de la transferencia por parte del Estado de la correlativa potestad en base a lo dispuesto en el artículo 150,2 , de la Constitución. Reglamentos que, como ya dijimos, corresponderá aprobar al Consell Executiu-y no al Parlament, como preveía el Anteproyecto de Estatuto-y que vendrán a desarrollar no una Ley de la Asamblea legislativa catalana, sino de las Cortes Generales. Pero-y esto es lo verdaderamente importante-también en este caso hay una Ley previa, aunque no la emane, como en el supuesto de las materias de competencia estatutaria de la Generalitat, el Parlament de la misma.

\section{EL CONTROL DE LAS POTESTADES NORMATIVAS}

\section{Planteamiento general y controi.es extrajudiciales}

A diferencia de lo que sucede en otros sistemas extranjeros-y, en concreto, en el italiano-, el único control existente en el Derecho español sobre las potestades normativas de las Comunidades Autónomas es, salvo un par de supuestos que pueden considerarse en cierto modo marginales, de carácter exclusivamente jurisdiccional. 
En efecto, y excepción hecha de los supuestos indicados y a los que luego aludiremos; ni las Cortes Generales ni el Gobierno tienen atribuido poder alguno de fiscalización, ni previo ni a posteriori, respecto de la emanación de Leyes y Reglamentos por parte de las citadas Comunidades. Sólo a los Tribunales y, en particular, al Tribunal Constitucional y a los que integran la jurisdicción contencioso-administrativa corresponde el ejercicio del aludido control. Control, como es obvio, únicamente de legitimidad-constitucional o legal, según los casos-y no de oportunidad política, como podría ocurrir, en cambio, si estuviera atribuido al Gobierno o al Parlamento. A través de dicho control se trata de verificar si las Leyes y los Reglamentos dictados por los aludidos entes autónomos se ajustan o no a los límites propios de los mismos.

Con carácter general, el artículo 153 de la Constitución establece, por lo que aquí interesa, que "el control de la actividad de los órganos de las Comunidades Autónomas se ejercerá: a) Por el Tribunal Constitucional, el relativo a la constitucionalidad de sus disposiciones normativas con fuerza de ley", y “c) Por la jurisdicción contencioso-administrativa, el de la administración autónoma y sus normas reglamentarias". El criterio que parece deducirse de tal dualidad de control al atribuir su ejercicio a uno y otro tipo de Tribunales, en función del rango de la disposición sujeta al mismo, se rompe, sin embargo, en el artículo 161, 2, del texto constitucional, según el cual "el Gobierno podrá impugnar ante el Tribunal Constitucional las disposiciones y resoluciones adoptadas por los órganos de las Comunidades Autónomas", en la medida en que el término disposiciones se interprete-como ha hecho la reciente Ley Orgánica del Tribunal Constitucional: artículo 76-en el sentido de normas reglamentarias. Veremos más tarde los problemas que plantea dicho precepto constitucional y los de la Ley que han venido a desarrollarle.

Por lo que respecta a la Generalitat, el Estatuto dispone lo siguiente en su artículo 40: “1. Las Leyes de Cataluña estarán excluidas del recurso contencioso-administrativo y únicamente sujetas al control de su constitucionalidad ejercido por el Tribunal Constitucional. 2. Contra los actos y acuerdos y las normas reglamentarias emanadas de los órganos ejecutivos y administrativos de la Generalidad, se podrá presentar recurso ante la jurisdicción contencioso-administrativa".

Ahora bien, los preceptos transcritos de la Constitución y del Estatuto de Autonomía de Catalunya deben entenderse referidos 
exclusivamente al control de las Leyes y Reglamentos dictados por las Comunidades Autónomas en general y por la Generalitat, respectivamente, en el ámbito de sus potestades normativas atribuidas estatutariamente.

En cambio, si tales potestades han sido conferidas extraestatutariamente a través de una de las vías previstas en los párrafos 1 y 2 del artículo 150 de la Constitución, a los tipos de control judicial referidos pueden añadirse otros, concretamente, los ejercitables por el Gobierno o por las Cortes Generales, según los casos.

Así, en primer lugar, el artículo 150, 1, tras señalar que "las Cortes Generales, en materias de competencia estatal, podrán atribuir a todas o a alguna de las Comunidades Autónomas la facultad de dictar, para sí mismas, normas legislativas en el marco de los principios, bases y directrices fijadas por una Ley cstalal", añade que "sin perjuicio de la competencia de los Tribunales, en cadia Ley marco se establecerá la modalidad del control de las Cortes Generales sobre estas normas legislativas de las Comunidades Autónomas".

Corresponde, pues, a las Cortes la determinación del tipo de control sobre las Leyes de desarrollo de las Leyes marco. En qué ha de consistir dicho control la Constitución no lo dice; lo remite a lo que disponga cada Ley marco. En cualquier caso, dada la libertad de que al respecto gozan las Cortes cabe imaginar desde el veto suspensivo o la devolución a la Asamblea legislativa de la Comunidad Autónoma de que se trate para nueva discusión y aprobación por la misma con una mayoría reforzada, hasta el sometimiento a ratificación por las Cortes de la Ley de desarrollo de la Ley marco, pasando por otras fórmulas intermedias. Y ello tanto en base a un juicio de legitimidad constitucional como de oportunidad política (no se olvide la función esencialmente política del Parlamento).

En segundo término, del enunciado del artículo 150,2 , de la Constitución se desprende la posibilidad de transferir a las Comunidades Autónomas mediante Ley orgánica en materias "de titularidad estatal que por su propia naturaleza sean susceptibles" de ello, entre otras facultades, la potestad legislativa o solamente la potestad reglamentaria. Pues bien, tanto en uno como en otro supuesto la Ley orgánica preverá "las formas de control que se reserve el Estado". En este caso, a diferencia del anterior, el control del ejercicio de las potestades transferidas-y, en concreto, las de naturaleza normativa, que son las que aquí importan-no sé encomienda exclusivamente a las Cortes, de modo que puede corresponder a éstas o al Gobierno, ser varias, igualmente, las modalidades y, por supuesto, los motivos en 
los que cabe basar el juicio. Tal como está redactado el precepto constitucional, no está descartada la posibilidad de que el control sobre el ejercicio de potestades legislativas se atribuya al Gobierno y no a las Cortes. Y no por el argumento del artículo $153, b$ ), de la Constitución, ya que entiendo que las potestades normativas-reglamentarias o legislativas-pueden transferirse, pero no delegarse. La delegación parece que debe limitarse a la atribución de facultades de gestión o ejecución en sentido estricto.

Cuanto acaba de decirse a propósito de las Comunidades Autónomas en general es aplicable, obviamente, a la Generalitat de Catalunya. Basta con que se pongan en marcha en relación con ella alguno de los mecanismos previstos en los apartados 1 y 2 del artículo 150 de la Constitución.

\section{Control por el Tribunal Constitucional}

Como ya hemos señalado, el Estatuto de Catalunya atribuye, de acuerdo con la Constitución, al Tribunal Constitucional el control de las Leyes de la Generalitat. No creemos necesario exponer aquí la problemática general sobre el recurso de inconstitucionalidad de las Leyes y, en concreto, de las de las Comunidades Autónomas, ya que no existe particularidad alguna con respecto a la de Catalunya. Nos remitimos por entero a la Ley Orgánica del Tribunal Constitucional y a la doctrina que se ocupa del tena. Destacaremos solamente algunas cuestiones que creemos de interés en función del objeto específico del presente trabajo.

En primer lugar, debemos señalar que, en base a la Ley citada, el Tribunal Constitucional puede controlar no sólo el ejercicio de la potestad legislativa por parte de la Generalitat, sino también el de la potestad reglamentaria, siempre que se plantee al respecto un conflicto de competencia por el Gobierno o el órgano ejecutivo superior de otra Comunidad Autónoma (arts. 60 y ss.). Ahora bien, dicho control sólo cabe-excepción hecha del supuesto a que me referiré a continuación-cuando quien plantee el conflicto considere que la disposición reglamentaria impugnada no respeta el orden de competencia establecido en la Constitución, en los Estatutos de Autonomía o en las Leyes orgánicas correspondientes (arts. 62 y 63). Debe alegarse, pues, como motivo del planteamiento del conflicto un vicio de competencia-y no cualquier otro-y, además, del tenor 
enunciado. Bien entendido que, como reza el artículo 67 de la misma Ley, "si la competencia controvertida hubiera sido atribuida por una Ley o norma con rango de Ley, el conflicto de competencias se tramitará desde su inicio o, en su caso, desde que en defensa de la competencia ejercida se invocase la existencia de la norma legal habilitante, en la forma prevista para el recurso de inconstitucionalidad".

El Gobierno-y sólo él-puede impugnar ante el Tribunal Constitucional, de acuerdo con los artículos 161, 2, de la Constitución y 76 y 77 de la referida Ley Orgánica, "las disposiciones normativas sin fuerza de Ley y resoluciones emanadas de cualquier órgano de las Comunidades Autónomas". En este caso, según el citado artículo 77, la impugnación, aparte de producir la importante consecuencia de suspender automáticamente la disposición (o resolución) recurrida "hasta que el Tribunal resuelva ratificarla o levantarla en plazo no superior a cinco meses", puede basarse en cualquier motivo. Lo cual me parece un notorio exceso por parte de la Ley Orgánica, que en este punto debe considerarse inconstitucional, ya que de una interpretación finalista y sistemática del artículo 161, 2, de la Constitución, debe deducirse que dicha impugnación sólo puede apoyarse en un motivo de inconstitucionalidad de la disposición reglamentaria impugnada (T. R. FERNANDEZ). En consecuencia, no debería caber una impugnación basada en motivos de mera ilegalidad-para eso están los Tribunales contenciosos; otra cosa es que, a menos que se modifique la vigente Ley jurisdiccional, esté el Gobierno legitimado para interponer ante aquéllos un recurso del tipo que estamos considerando-, y mucho menos en razones de oportunidad, dada la naturaleza del órgano llamado a resolver y el principio de autonomía política consagrado constitucionalmente a favor de las Comunidades Autónomas.

En segundo término, debe tenerse en cucnta que la Ley Orgánica del Tribunal Constitucional establece, de un modo un tanto discutible, que "para apreciar la conformidad o disconformidad con la Constitución de una Ley, disposición o acto con fuerza de Ley del Estado o de las Comunidades Autónomas, el Tribunal considerará, además de los preceptos constitucionales, las Leyes que, dentro del marco constitucional, se hubieren dictado para delimitar las competencias del Estado y las diferentes Comunidades Autónomas o para regular o armonizar el ejercicio de las competencias de éstas". Es decir, la Ley citada amplía el módulo o patrón conforme al cual ha de juzgarse sobre la constitucionalidad o no de una norma con valor 
de Ley, módulo que parece debiera ser exclusivamente la Constitución y sus principios informadores.

Por último, cabe plantear el tema del control de la adecuación de las Leyes de la Generalitat a su propio Estatuto. Pues bien, si una Ley aprobada por el Parlament viola éste, en realidad lo está modificando a través de un procedimiento-el de la Ley ordinaria-distinto y no previsto por la Constitución (arts. 56 y 57). En la medida en que infrinja el procedimiento citado, estará violando la Constitución. Por consiguiente, dicha Ley será inconstitucional y como tal podrá ser declarada por el Tribunal Constitucional previa impugnación ante el mismo.

Por otro lado, el Estatuto de Catalunya ha establecido no un verdadero recurso de "antiestatutoriedad", sino una especie de control previo-de un modo que recuerda el mecanismo del Consejo Constitucional francés-de la "estatutoriedad" de determinados proyectos o proposiciones de Ley. En efecto, de acuerdo con el artículo 41, l, "sin perjuicio de lo que dispone el apartado l del artículo anterior (relativo al control de constitucionalidad por el Tribunal Constitucional), una Ley de Cataluña creará y regulará el funcionamiento de un Organismo de carácter consultivo, que dictaminará, en los casos que la propia Ley determine, sobre la adẹcuación al presente Estatuto de los proyectos o proposiciones de Ley sometidas a debate y aprobación del Parlamento de Cataluña". Habrá que esperar a la Ley reguladora del organismo en cuestión para ver cuál es la eficacia del aludido dictamen. Pero si no es vinculante, el Parlament será libre de aprobar o no el proyecto o proposición de Ley, aunque aquél sea desfavorable (otra cosa es la repercusión política que ello puede tener).

\section{Control por los Tribunales contenciosos}

En relación con el control jurisdiccional contencioso de las disposiciones reglamentarias de la Generalitat, quisiera apuntar solamente dos cuestiones. Una, la de las relaciones entre el recurso contencioso y el recurso de inconstitucionalidad cuando un mismo Reglamento sea impugnado por sujetos distintos-por ejemplo, un particular y el Gobierno, respectivamente-en una y otra vía. Circunstancia que puede darse perfectamente en la práctica y que recuerda el problema-que fue más teórico que real-de las relaciones entre el recurso contencioso y el recurso de contrafuero a partir de 
la Ley Orgánica del Estado. La Ley Orgánica del Tribunal Constitucional nada ha previsto expresamente al respecto. Una solución sería, a mi modo de ver, la de suspender el curso del proceso contencioso hasta el fallo del Tribunal Constitucional (argumento por analogía del supuesto a que se refiere el artículo 61,2 , de la Ley últimamente citada, relativo a los conflictos de competencia).

La otra cuestión es que de una interpretación combinada de los artículos 24 y 106 de la Constitución debe considerarse admitida en todo caso la legitimación individual por interés directo contra los Reglamentos dictados por la Administración de la Generalitat (al igual que contra los procedentes de la del Estado). 


\section{NOTA BIBLIOGRAFICA}

La mención que de distintos autores se hace en el texto anterior debe entenderse referida a las siguientes obras y trabajos:

M. BASSOLS: "Las diversas manifestaciones de la potestad reglamentaria en la Constitución", Revista de Administración Pública, 1979, 88, págs. 107 y ss.

J. L. Carro y R. Gómez-Ferrer: "La potestad reglamentaria del Gobierno y la Constitución", Revista de Administración Pública, 1978, 87, págs. 161 y ss.

L. Cosculluela: "La Región", en la obra colectiva dirigida por S. MARTIN-RETORTILlo, Descentralización administrativa y organización política. Madrid, Ed. Alfaguara, 1973, III, págs. 311 y ss.

- "En torno a las transferencias de funciones a las Comunidades Autónomas", Revista Española de Derecho Administrativo, 1978, 18, págs. 367 y ss.

R. Entrena: Curso de Derecho Administrativo, I, 6. a ed., Madrid, Ed. Tecnos, 1979.

T. R. FERnÁnDEZ: "El sistema de distribución de competencias entre el Estado y las Comunidades Autónomas", RevisTa DE EsTudios DE LA VIDA LOCAL, 1979, 201, págs. 9 y ss.

- "Reflexiones en torno al artículo 161, 2, de la Constitución", Boletín Informativo del Departamento de Derecho Político, UNED, 1979, 3, págs. 7 y ss.

- "El problema de los límites de la potestad legislativa regional", Documentación Administrativa, 1979, 182, págs. 11 y ss.

E. García de EnTerría y T. R. Fernández: Curso de Derecho Administrativo, I, 3. ${ }^{\mathrm{a}}$ ed, Madrid, Ed. Civitas, 1979.

D. JesCH: Ley y Administración, trad. cast., Madrid, Ed. IEA, 1977.

L. MaRTín RebOllo: "Incidencia de la nueva organización territorial en el contencioso-administrativo (El control jurisdiccional de las Comunidades Autónomas), Documentación Administrativa, 1979, 182, págs. 489 y ss.

S. Martín-Retortillo: "Presupuestos constitucionales de la función administrativa en el Derecho positivo español", Revista de Administración Pública, 1958, 26, págs. 11 y ss. 
S. MuÑoz MaChado: "El Gobierno y la Administración regional”, en la obra colectiva dirigida por T. R. FERNANDEZ, Las autonomías regionales. Aspectos políticos y jurídicos. Madrid. Ed. Instituto Nacional de Prospectiva, 1977, págs. 361 y ss.

- Las potestades legislativas de las Comunidades Autónomas, Madrid, Ed. Civitas, 1979.

J. SALAS: "El tema de las competencias: instrumentación de las relaciones entre el Estado y la Administración local desde la perspectiva de la descentralización territorial", en la obra colectiva Descentralización, cit., II, págs. 303 y ss.

- Los Decretos-leyes en la Constitución española de 1978, Madrid, Ed. Civitas, 1979.

J. Tornos: "La intervención de las Comunidades Autónomas en la economia”, Revista Española de Derecho Administrativo, 1979, 21 , págs. 221 y ss. 